Cite this: J. Mater. Chem. C, 2014, 2 , 5487

Received 17th March 2014 Accepted 22nd April 2014

DOI: $10.1039 / c 4 t c 00533 c$

www.rsc.org/MaterialsC

\section{4-Methylresorcinol based bent-core liquid crystals with azobenzene wings - a new class of compounds with dark conglomerate phases $\uparrow$}

\begin{abstract}
Mohamed Alaasar, ${ }^{* a b}$ Marko Prehm, ${ }^{a}$ Marcel Brautzsch ${ }^{a}$ and Carsten Tschierske ${ }^{* a}$
Stochastic achiral symmetry breaking in soft matter systems, leading to conglomerates of macroscopically chiral domains (so-called dark conglomerate $=\mathrm{DC}$ phases) is of contemporary interest from a fundamental scientific point of view as well as for numerous potential applications in chirality sensing and noncentrosymmetric materials. Herein we report the synthesis and investigation of first azobenzene containing bent-core mesogens derived from 4-methylresorcinol forming DC phases with a new structure, distinct from the known fluid sponge-like distorted smectic phases as well as from the helical nano-filament phases (HNF phases, $B_{4}$ phases). The effects of chain length and other structural modifications on achiral symmetry breaking were investigated. Homologues with relatively short alkyl chains form achiral intercalated lamellar $L C$ phases ( $B_{6}$ phases), but on increasing the chains, these are replaced by the chiral and optically isotropic DC phases. Compounds with the longest alkyl chains form low birefringent crystalline conglomerates which represent less distorted versions of the optically isotropic DC-phases. Introducing additional peripheral substituents at both outer rings removes the DC phases. The DC phases were also removed and replaced by modulated smectic phases if the azo groups were replaced by ester units, showing that azo groups favour DC phase formation with new nanostructures, distinct from the previously known types.
\end{abstract}

\section{Introduction}

Since the discovery of polar order and chirality in the liquid crystalline (LC) phases of compounds with a bent aromatic core (bent-core liquid crystals $=$ BCLCs) ${ }^{1}$ this field has become a thrust area of liquid crystal research by providing a significant impact on the general understanding of molecular selfassembly in soft condensed matter. ${ }^{2,3}$ Moreover, these materials are also of significant interest for numerous practical applications, as ferroelectrica, flexoelectrica and pyroelectrica, ${ }^{4}$ for command surfaces and sensors, ${ }^{5}$ non linear optical applications ${ }^{6}$ and in fast switching electrooptical devices. ${ }^{7}$ A great fraction of contemporary interest is focussed on the so-called dark conglomerate phases (DC phases).$^{8-18}$ The common feature of these DC phases is the absence of birefringence due to a local distortion of long range periodicity and the inherent phase chirality indicated by stochastic achiral symmetry breaking, leading to conglomerates of macroscopically chiral domains. These DC phases can be subdivided

${ }^{a}$ Institute of Chemistry, Martin Luther University Halle-Wittenberg, Kurt Mothes Str. 2, D-06120 Halle (Saale), Germany.E-mail: carsten.tschierske@chemie.uni-halle.de

${ }^{b}$ Department of Chemistry, Faculty of Science, Cairo University, Giza, Egypt. E-mail: malaasar@sci.cu.edu.eg

$\dagger$ Electronic supplementary information (ESI) available. See DOI: $10.1039 / \mathrm{c} 4 \mathrm{tc} 00533 \mathrm{c}$ into the liquid crystalline smectic phases (sponge phases) $)^{\mathbf{8 - 1 5}}$ and the soft crystalline helical nanofilament phases (HNF phases, also assigned as $\mathrm{B}_{4}$ phases). ${ }^{\mathbf{1 6 - 1 9}}$ In the sponge type DC phases, layers without in-plane order are strongly deformed in a nonregular way, so that uniformly oriented regions become smaller than the wavelength of light. In contrast, the HNF phases are composed of helical filaments with a crystalline packing of the aromatic cores in twisted ribbons, here only the chains are in a disordered state. As there is no preferred direction for these filaments these phases appear optically isotropic. The major tool for distinguishing these two structures is XRD, where the wide angle scattering around $d=0.45$ $\mathrm{nm}$ is completely diffuse for the LC sponge phases whereas for the soft crystalline HNF phases a series of relatively sharp scattering could be found in this region. ${ }^{16 a, 20,21}$ The reduced symmetry as a result of the tilted organization of molecules in polar layers (layer chirality), ${ }^{3,16}$ the collective segregation of chiral molecular conformations and a combination of both are considered as possible origins of the remarkable chirality and mirror symmetry breaking in these soft matter structures. $^{2 \boldsymbol{a}, \boldsymbol{b}, \mathbf{8 , 1 7 a , 2 2}}$ HNF phases might become interesting materials for a number of applications, such as organic semiconductors for thin-film transistors and solar cells, ${ }^{23}$ as thin-film polarizers, ${ }^{22}$ as nonlinear optical materials ${ }^{24}$ as well as for the detection and amplification of chirality. ${ }^{25}$ 
Interestingly, almost all of the known BCLCs with HNF phases incorporate the hydrolytically unstable benzylideneaniline (Schiff base) moiety with the exception of only very few recent examples. $^{26-28}$ This calls for new materials with DC phases, showing enhanced chemical stability and providing new phase sequences involving the HNF phases. A broader variety of different molecular structures could also lead to an improved understanding of the molecular structural factors governing the formation of distinct subtypes of DC phases, thus providing rules for the directed design of such materials.

BCLCs incorporating azo $(-\mathrm{N}=\mathrm{N}-)$ linkages represent versatile materials due to their photochromic effects in addition to high birefringence and high polarizability, leading to significant nonlinear optical activity. ${ }^{6,29,30}$ The cis-trans isomerisation of the azo linkage in the presence of UV light could be used, for example, in high-density data storage systems, for sensors, photonic switches and molecular logic gates. ${ }^{31}$ Though a variety of azobenzene based BCLCs with interesting properties have been reported, ${ }^{29,32-34}$ until recently no such BCLCs with DC phases have been available; only bent dimesogens combining two rod-like azobenzene units via an oddnumbered alkylene spacer were reported. ${ }^{27}$ We have found that iodine $^{28}$ or bromine ${ }^{34 a}$ substitution in 4-position at the bent central resorcinol unit of azobenzene based BCLCs leads to a new type of DC-phases (Scheme 1). ${ }^{28}$ Hence, it appears that the size of the halogens is of importance. Bulky halogen atoms like bromine $\left(\mathrm{cv}=0.33 \mathrm{~nm}^{3}\right)^{35}$ or iodine $\left(\mathrm{cv}=0.45 \mathrm{~nm}^{3}\right),{ }^{35}$ seem to be favourable for formation of DC phases, whereas no DC phases were found for BCLC with hydrogen ${ }^{32 e}$ or smaller halogens in the same position (see Scheme $1 ; \mathrm{F}: \mathrm{cv}=0.13 \mathrm{~nm}^{3}$; $\left.\mathrm{Cl}: \mathrm{cv}=0.27 \mathrm{~nm}^{3}\right) \cdot{ }^{34,35}$ Hence, the question arose if azobenzene BCLCs with other bulky groups at the bent core, having a size comparable to iodine/bromine, could also lead to azobenzene based BCLCs showing DC phases. The methyl group has a size $\left(\mathrm{cv}=0.32 \mathrm{~nm}^{3}\right)^{35}$ comparable to bromine but it is almost nonpolar in contrast to the C-halogen bonds which introduce a significant dipole moment.

Here we report a series of new BCLCs derived from 4-methylresorcinol $^{36,37}$ possessing two azobenzene side arms (An, see Scheme 2). These compounds show $B_{6}$ phases if the terminal chains are short and a new type of dark conglomerate phases if the chains are sufficiently long. Besides these isotropic DC

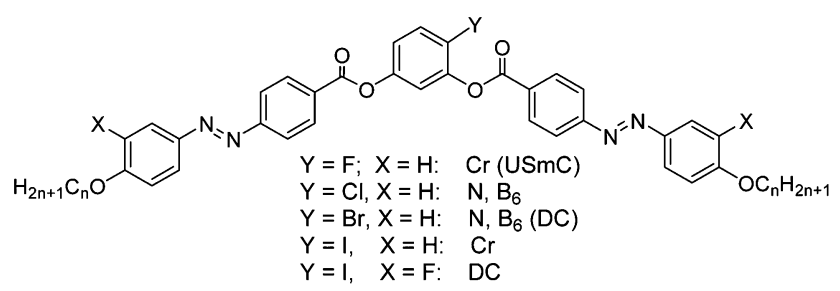

Scheme 1 LC phases found for 4-halogenoresorcinol based bentcore mesogens with azobenzene wings (abbreviations: $\mathrm{Cr}=$ crystalline solid, USmC = undulated smectic phase; $N=$ nematic phase, $B_{6}=$ intercalated smectic phase formed by ribbons with only short range register; $D C=$ dark conglomerate phase; phases in brackets were observed only for one homologue in a small temperature range). ${ }^{28,34 a}$

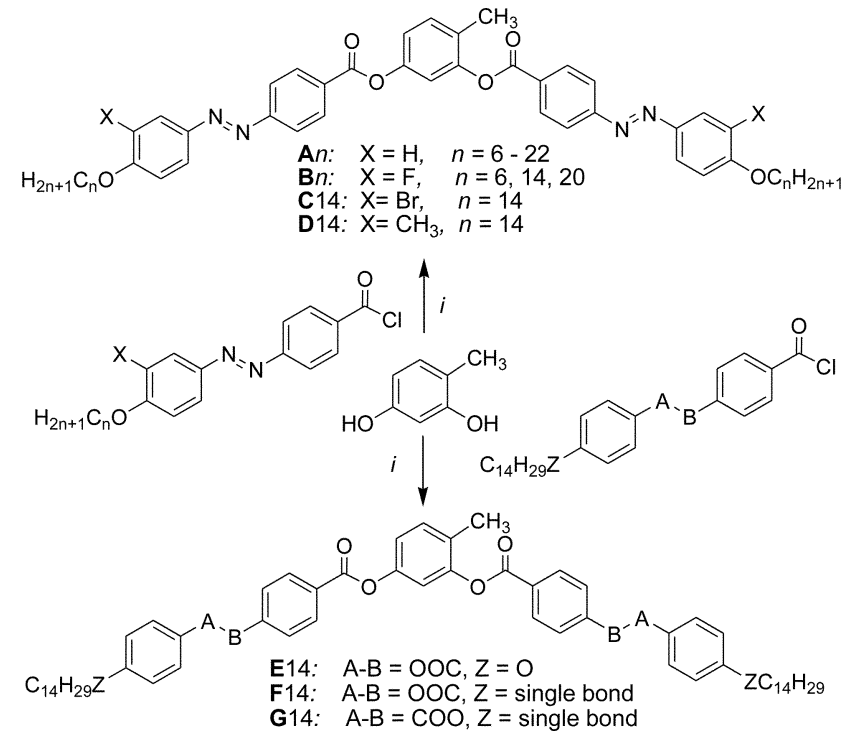

Scheme 2 Structures of the 4-methylresorcinol derived bent-core liquid crystalline compounds $\mathrm{A} n-\mathrm{G} n$ (for $\mathrm{A} n$ : $n$ is an even number except A9) and their synthesis; reagents and conditions: (i) $\mathrm{Et}_{3} \mathrm{~N}$, pyridine, $\mathrm{CH}_{2} \mathrm{Cl}_{2}$, reflux, $6 \mathrm{~h}$.

phases also a birefringent crystalline conglomerate was observed for a long chain compound. The formation of this phase depends on the applied cooling rates and the transition between the isotropic and birefringent types of conglomerate phases was studied. In addition, the effect of lateral groups $\mathrm{X}$ (see Scheme 2, $\mathrm{X}=\mathrm{F}, \mathrm{Br}, \mathrm{CH}_{3}$ ) at the outer rings of these BCLCs (compounds Bn, C14 and D14, respectively) has been investigated. The phase behaviour of these new compounds is compared with related compounds incorporating terephthalate or benzoate based wing groups instead of the azobenzenes, either reported in the literature ${ }^{36}$ or synthesized herein (E14, F14 and G14 see Section 3.6).

\section{Experimental}

Synthesis

The synthesis of the target BCLCs $\mathbf{A} / \boldsymbol{n}-\mathbf{D} / \boldsymbol{n}$ with azobenzene wings was performed as shown in Scheme 2 by acylation of 4 methylresorcinol with 4-(4- $n$-alkoxyphenylazo)benzoyl chlorides $(\mathrm{X}=\mathrm{H})$ or their 3-substituted derivatives with $\mathrm{X}=\mathrm{F}, \mathrm{CH}_{3}, \mathrm{Br}$ (see Scheme S1 $\dagger$ ). For the synthesis of compounds E/14-G/14 appropriately substituted benzoyl chlorides (see Scheme S2 $\dagger$ ) were used for the acylation reactions. ${ }^{37}$ Details of the synthesis of the intermediates and final compounds as well as analytical data are reported in the ESI. $\dagger$

\section{Methods}

The mesophase behaviour and transition temperatures were measured using a Mettler FP-82 HT hot stage and a control unit in conjunction with a Nikon Optiphot-2 polarizing microscope. The associated enthalpies were obtained from DSC-thermograms which were recorded on a Perkin-Elmer DSC-7, the 
heating and cooling rate was $10 \mathrm{~K} \mathrm{~min}^{-1}$. Electro-optical switching characteristics were examined in $6 \mu \mathrm{m}$ polyimide coated ITO cells (EHC Japan) using the triangular-wave method. XRD patterns were recorded with a 2D detector (Vantec-500, Bruker). Ni filtered and pin hole collimated $\mathrm{CuK}_{\alpha}$ radiation was used. The exposure time was $15 \mathrm{~min}$ and the sample to detector distance was 8.95 and $26.7 \mathrm{~cm}$ for small angle and wide angle scattering experiments, respectively. Samples were aligned by slow cooling (rate: $1-0.1 \mathrm{~K} \mathrm{~min}^{-1}$ ) of a small droplet of the compound on a glass plate and takes place at the sample-air interface. The samples were held on a temperature-controlled heating stage.

DFT computation was carried out with the Gaussian 09 package. $^{38}$ Geometry optimization was performed with the B3LYP functional and the LAN L2 DZ basis set. The solvation model was IEFPCM with solvent chlorobenzene.

\section{Results and discussion}

\subsection{Overview over the LC phases formed by compounds An- Dn}

The thermal behaviour of all synthesized compounds was studied by polarizing optical microscopy (POM) and differential scanning calorimetry (DSC). The transition temperatures $\left({ }^{\circ} \mathrm{C}\right)$, the associated phase transition enthalpies $\left(\mathrm{kJ} \mathrm{mol}^{-1}\right)$ and the phase sequences of compounds An, Bn, C14 and D14 are given in Table 1 . All compounds are thermally stable as confirmed by the reproducibility of thermograms in several heating and cooling cycles. Related compounds E/14-G/14 with phenylbenzoate wing groups instead of the azobenzenes, synthesized for comparison purposes, are described and discussed in Section 3.6.

\section{2 $B_{6}$-type intercalated smectic phases of the short chain compounds $\mathrm{A} 6$ and $\mathrm{A} 8$}

Compounds An without lateral substituents at the outer rings of the bent-core structure exhibit two different types of mesophases. On heating the shortest homologue (A6, with $n=6$ ) a transition from the crystalline state to a focal-conic fan-shaped texture is observed at $T=124{ }^{\circ} \mathrm{C}$ (Fig. 1a). The dark extinctions are parallel to a polarizer and an analyzer, indicating an average orthogonal or anticlinic tilted smectic phase. No homeotropic alignment with pseudoisotropic areas or with birefringent Schlieren texture, as typical for SmA or SmC phases, respectively, could be achieved by shearing the sample. Instead, a fine fan-texture is immediately reformed after releasing shear stress (see Fig. S2†), as typical for intercalated smectic phases of bentcore mesogens, assigned as $\mathrm{B}_{6}$ phases.

The XRD pattern (Fig. $1 \mathrm{~b}$ and c) shows only one sharp peak in the small angle region corresponding to a $d$-value of $2.0 \mathrm{~nm}(T=$ $\left.80^{\circ} \mathrm{C}\right)$, which is smaller than half of the molecular length $\left(L_{\mathrm{mol}}\right)$ in a conformation with a $120^{\circ}$ bent aromatic unit and the alkyl chains in the most stretched all-trans conformation. For compound $\mathrm{A6} L_{\mathrm{mol}}$ is between 4.3 and $4.5 \mathrm{~nm}$, depending on the assumed conformation shown in Fig. S1. $\dagger$ This confirms the intercalated $\mathrm{B}_{6}$-type smectic phase deduced from optical investigations. According to the present understanding, this is a frustrated smectic phase with layers broken into ribbons and adopting a staggered organization with only short range periodicity between the ribbons (see Fig. 1d); the layer frustration takes place in the direction perpendicular to the molecular bending plane (Fig. 1d). ${ }^{39,40}$

The wide angle scattering is diffuse and has a maximum at $0.43 \mathrm{~nm}$, in line with the LC state of this phase. For an aligned sample this scattering is split into four maxima indicating the presence of a tilt of about $26^{\circ}$ (Fig. $1 \mathrm{~b}$ and $\mathrm{S} 12 \dagger$ ). This tilt could arise either from a tilt of the molecular bending planes, or alternatively, from the inherently tilted orientation of the individual rod-like wings of the bent-core mesogens, similar to anticlinic SmC phases. ${ }^{41}$ The latter would be in line with recent microbeam XRD results obtained for $\mathrm{B}_{6}$ phases of Schiff base compounds. ${ }^{39 a}$ In this case the orientation of the molecules would be on average orthogonal and the splitting is related to the angle of the molecular bent of $128^{\circ}$ which is in good agreement with the geometry provided by the molecular structure. This would also be in line with the optical textures which have the extinction brushes strictly parallel to the polarizers (see Fig. 1a). However, the measured $d$ value is a bit shorter than half the molecular length $\left(2 d / L_{\mathrm{mol}} \sim 0.9\right)$ which in this case must be attributed to partial intercalation and conformational disorder of the alkyl chains. On cooling A6 from the isotropic state the $\mathrm{B}_{6}$ phase appears at $T=129^{\circ} \mathrm{C}$ and remains on cooling down to room temperature without visible crystallization of the sample (for DSC traces, see Fig. 2a), but the sample becomes glass-like solid without any change of the texture at $\sim 40$ ${ }^{\circ} \mathrm{C}$. This might indicate a transition to a glassy state of the $\mathrm{B}_{6}$ phase or an isomorphous crystallization. As no clear DSC peak (only a small hump between 40 and $50{ }^{\circ} \mathrm{C}$, see Fig. 2a) was observed in the cooling traces and crystallization is observed $>35$ ${ }^{\circ} \mathrm{C}$ on heating, a glassy $\mathrm{B}_{6}$ phase $\left(\mathrm{gB}_{6}\right)$ appears more likely.

In electrooptical investigations using a triangular wave voltage no current peak could be observed in the whole temperature range of this mesophase up to a voltage of $200 \mathrm{~V}_{\mathrm{pp}}$ in a $6 \mu \mathrm{m}$ ITO cell. These observations, together with the relatively high transition enthalpy value of $\Delta H=12.3 \mathrm{~kJ} \mathrm{~mol}^{-1}$ for the Iso-LC transition at $T=129{ }^{\circ} \mathrm{C}$ are in line with the suggested $\mathrm{B}_{6}$ phase. With increasing chain length $(n=8$ and 9$)$ the $\mathrm{B}_{6}$ phase is retained but the Iso- $\mathrm{B}_{6}$ transition temperature decreases to $96{ }^{\circ} \mathbf{C}$ for $\mathbf{A 8}$ and to $87^{\circ} \mathrm{C}$ for $\mathbf{A 9}$, and the $\mathrm{B}_{6}$ phase becomes monotropic (metastable) for these two compounds.

\subsection{Competition between $\mathrm{B}_{6}$ and DC phases in $\mathrm{A9}$}

On cooling the $\mathrm{B}_{6}$ phase of $\mathbf{A 9}$ a highly viscous, almost solidlike optically isotropic mesophase starts to grow at $T=85^{\circ} \mathrm{C}$ (Fig. 3a and b). Uncrossing the polarizers by a small angle leads to the appearance of dark and bright domains. Uncrossing the polarizer in the opposite direction reverses the dark and bright domains (Fig. 3c and d). Rotating the sample between crossed polarizers does not lead to any change and this indicates that the distinct regions represent chiral domains with opposite handedness, as typical for dark conglomerate phases (DC phases). The distribution of the areas of domains with opposite chirality is on average $1: 1$. 
Table 1 Phase transition temperatures $\left(T /{ }^{\circ} \mathrm{C}\right)$, mesophase types, and transition enthalpies $\left(\Delta H / \mathrm{kJ} \mathrm{mol}^{-1}\right.$, values in square brackets) of compounds $\mathrm{An}, \mathrm{B} n, \mathrm{C} 14$ and $\mathrm{D} 14^{a}$

\begin{tabular}{|c|c|c|c|c|}
\hline A6 & 6 & $\mathrm{H}$ & Cr $124[41.0] \mathrm{B}_{6} 131$ [11.9] Iso & Iso $129[12.3] \mathrm{B}_{6}$ \\
\hline A8 & 8 & $\mathrm{H}$ & Cr 111 [35.9] Iso & Iso $96[11.1] \mathrm{B}_{6} 62[9.1] \mathrm{Cr}$ \\
\hline A9 & 9 & $\mathrm{H}$ & $\begin{array}{l}\text { Cr } 110[37.4] \text { Iso } \\
\text { DC } 100[22.7] \text { Iso }^{b}\end{array}$ & $\begin{array}{l}\text { Iso } 87[9.4] \mathrm{B}_{6} 67[16.5] \mathrm{Cr}^{f} \\
\text { Iso } 87[9.4] \mathrm{B}_{6} \sim 85 \mathrm{DC}[\geq 9.1] 67 \mathrm{Cr}^{f}\end{array}$ \\
\hline $\mathbf{A 1 0}$ & 10 & $\mathrm{H}$ & $\begin{array}{l}\text { Cr } 107[37.4] \text { Iso } \\
\text { DC } 100[25.5] \text { Iso }^{c}\end{array}$ & Iso $87[24.1] \mathrm{DC}$ \\
\hline A16 & 16 & $\mathrm{H}$ & DC 102 [40.8] Iso & Iso $90[43.9] \mathrm{DC}$ \\
\hline A18 & 18 & $\mathrm{H}$ & DC 103 [49.6] Iso & Iso $93[51.7]$ DC \\
\hline A20 & 20 & $\mathrm{H}$ & $\begin{array}{l}\mathrm{Cr}^{[*]} 99 \text { DC } 104[68.0]^{d} \text { Iso } \\
\text { DC } 104[56.7] \text { Iso }^{e}\end{array}$ & $\begin{array}{l}\text { Iso } 92[70.8] \mathrm{Cr}^{[*]} \\
\text { Iso } 95[59.0] \mathrm{DC}^{g}\end{array}$ \\
\hline $\mathbf{A 2 2}$ & 22 & $\mathrm{H}$ & $\mathrm{Cr}^{[*]} 105[73.2]$ Iso & Iso $96[76.5] \mathrm{Cr}^{[*]}$ \\
\hline B6 & 6 & $\mathrm{~F}$ & Cr 112 [41.3] Iso & Iso $88[8.6] \mathrm{SmC}_{\mathrm{a}} \mathrm{P}_{\mathrm{A}} 67[10.5] \mathrm{Cr}^{h}$ \\
\hline B14 & 14 & $\mathrm{~F}$ & Cr 90 [32.9] $\mathrm{SmC}_{\mathrm{a}} \mathrm{P}_{\mathrm{A}} 95$ [12.8] Iso & Iso $90[15.2] \mathrm{SmC}_{\mathrm{a}} \mathrm{P}_{\mathrm{A}} 74[39.8] \mathrm{Cr}$ \\
\hline $\mathbf{B 2 0}$ & 20 & $\mathrm{~F}$ & Cr $95[93.0]$ Iso & Iso $92[16.0] \mathrm{SmC}_{\mathrm{a}} \mathrm{P}_{\mathrm{A}} 82[77.7] \mathrm{Cr}$ \\
\hline C14 & 14 & $\mathrm{Br}$ & Cr $78[77.2]$ Iso & Iso $30[53.2] \mathrm{Cr}$ \\
\hline D14 & 14 & $\mathrm{CH}_{3}$ & Cr 79 [47.9] Iso & Iso $33[0.9] \mathrm{SmC}<20 \mathrm{Cr}$ \\
\hline
\end{tabular}

${ }^{a}$ Before measurement the compounds were melted and heated to $150{ }^{\circ} \mathrm{C}$ to remove traces of enclosed solvent, afterwards they were cooled with $10 \mathrm{~K}$ $\mathrm{min}^{-1}$ to room temperature; the phase transition temperatures (peak temperatures) were taken from the following heating and cooling scans at $10 \mathrm{~K}$ $\min ^{-1}$, if not otherwise specified; abbreviations: $\mathrm{SmC}=$ synclinic tilted birefringent smectic phase; $\mathrm{SmC}_{\mathrm{a}} \mathrm{P}_{\mathrm{A}}=$ anticlinic tilted antiferroelectric SmC phase; Iso $=$ isotropic liquid; $\mathrm{Cr}^{[*]}=$ crystalline phase composed of a conglomerate of chiral domains, for other explanations, see Scheme 1. ${ }^{b}$ Obtained on heating after previous cooling to $75{ }^{\circ} \mathrm{C}$ with $10 \mathrm{~K} \mathrm{~min}^{-1}$. ${ }^{c}$ Obtained on heating after previous cooling to $80{ }^{\circ} \mathrm{C}$ with $20 \mathrm{~K}$ min ${ }^{-1}$. ${ }^{d}$ Total enthalpy for both transitions. ${ }^{e}$ Obtained on heating after previous cooling to $80{ }^{\circ} \mathrm{C}$ with $2 \mathrm{~K} \mathrm{~min}^{-1}$. ${ }^{f}$ The actual phase sequence strongly depending on conditions, see DSC traces in Fig. $2 \mathrm{~b}$; transition enthalpy value could not be determined for the $\mathrm{B}_{6}-\mathrm{DC}$ transition (see Section 3.3). ${ }^{g}$ Cooling with $2 \mathrm{~K} \mathrm{~min}^{-1} .{ }^{h}$ Partial crystallization.

The formation of the DC phase is slow and on further cooling the remaining $\mathrm{B}_{6}$ phase rapidly crystallizes with formation of a birefringent crystalline phase (see Fig. 3b) at $T=67^{\circ} \mathrm{C}$, while the DC phase only very slowly crystallizes. On heating the areas of the DC phase go to the isotropic liquid state at $T=100{ }^{\circ} \mathrm{C}$, while the birefringent crystalline regions of the sample melt to a clear liquid at $T=110{ }^{\circ} \mathrm{C}$. This indicates that the $\mathrm{B}_{6}$-phase, formed first, is thermodynamically unstable and upon annealing is replaced by the isotropic DC phase and a birefringent crystalline phase. Formation of the DC phase is in competition with fast crystallization, but the DC phase once formed crystallizes only slowly (see Fig. S3 $\dagger$ ). However, after slow cooling $\left(2 \mathrm{~K} \mathrm{~min}^{-1}\right.$ ) to $\sim 70{ }^{\circ} \mathrm{C}$, followed by immediate heating, a uniform DC phase can be obtained (see $3^{\text {rd }}$ heating curve in Fig. 2b). ${ }^{42}$

\subsection{DC phases of the long chain compounds A10-A22}

3.4.1 Optical and calorimetric investigations. For the next homologues with $n=10-18$ the DC phase is the only observed mesophase and it is directly formed upon cooling the isotropic liquid (see Fig. S4 $\uparrow$ for textures observed for compound A14). The growth process from the isotropic liquid, as observed between slightly uncrossed polarizers, is shown for compound A10 in Fig. 4. The distinct chiral domains grow with a circular shape (Fig. $4 \mathrm{a}-\mathrm{c}$ ) and finally coalesce to a mosaic-like pattern with sharp linear boundaries, representing the Voronoi cells separating the germs of circular domain growth (Fig. 4d). In this respect the formation of the DC phases reported herein is distinct from previously reported cases, showing fractal growth. ${ }^{43}$

The melting of the DC phases (DC-Iso-transition) takes place around $100-104{ }^{\circ} \mathrm{C}$ and the crystallization of the DC phase (IsoDC transition) is found between 87 and $95{ }^{\circ} \mathrm{C}$ for all compounds A10-A20 and both transition temperatures increase slightly with rising alkyl chain length (see Table 1 and Fig. 5a). Hence, there is a supercooling of this phase transition by about $10 \mathrm{~K}$ (peak temperatures at scanning rates of $10 \mathrm{~K} \mathrm{~min}^{-1}$ ). The formation of the DC phases is associated with relatively high 
a)

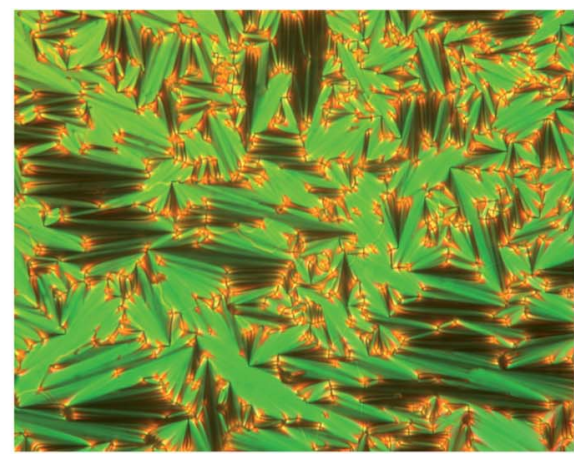

b)

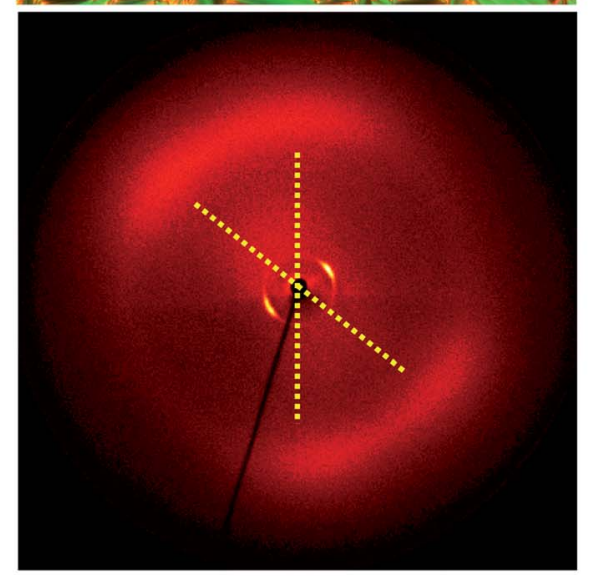

c)

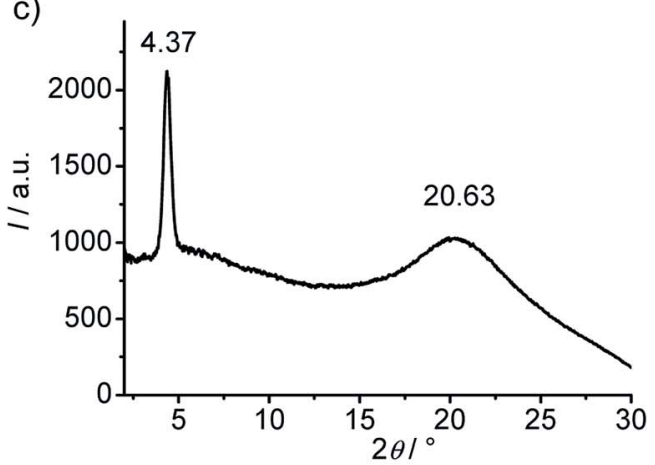

d)

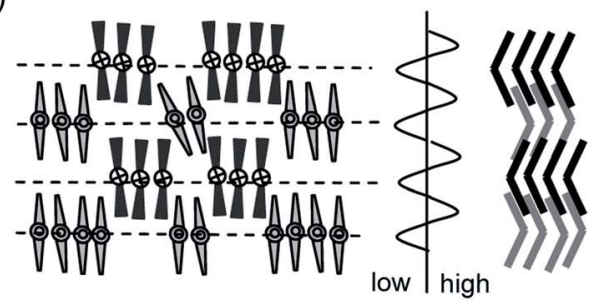

Fig. 1 Compound A6. (a) Texture (crossed polarizers) as observed for the $\mathrm{B}_{6}$ phase at $T=120^{\circ} \mathrm{C}$ (on cooling, textures observed after applying shear stress are shown in Fig. S2 $†$ ); (b) XRD pattern of an aligned sample of the $\mathrm{B}_{6}$-phase at $80^{\circ} \mathrm{C}$; (c) $2 \theta$-scan over this pattern and (d) the proposed model of the molecular organization in the $B_{6}$ phase, left: view along the bending direction, right: side view perpendicular to the molecular bending plane (in this direction the ribbons are quasi infinite) and the assumed electron density modulation profile in the middle. ${ }^{41}$

transition enthalpies, ranging between $\Delta H \sim 24$ and $59 \mathrm{~kJ} \mathrm{~mol}^{-1}$ (measured in cooling scans), strongly rising with growing alkyl chain length from A10 to A20 (see Table 1 and Fig. 5a).
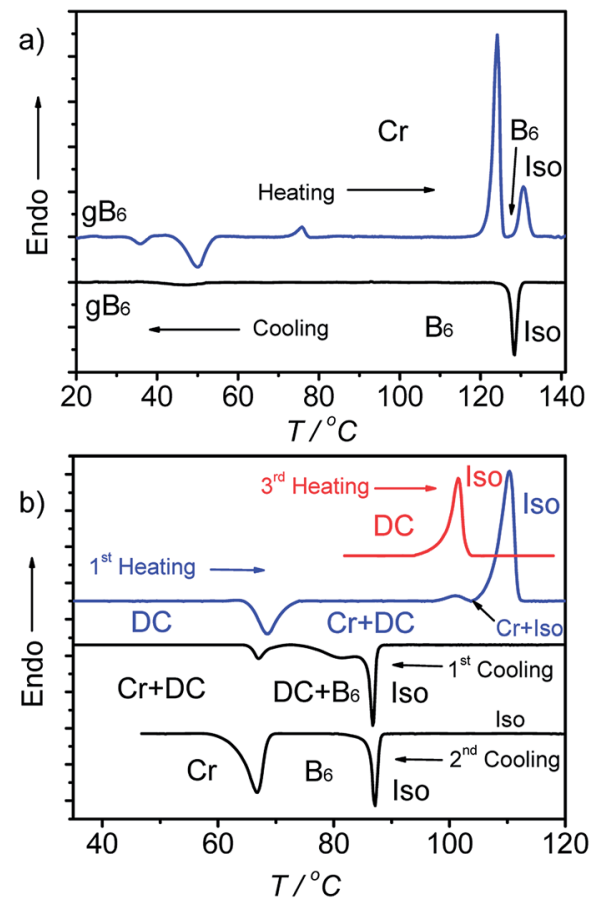

Fig. 2 DSC heating and cooling traces of compounds (a) A6 and (b) A9 in heating and cooling runs with a rate of $10 \mathrm{~K} \mathrm{~min}^{-1}$ (the 3 rd heating was recorded after slow cooling with $2 \mathrm{~K} \mathrm{~min}^{-1}$ to $80^{\circ} \mathrm{C}$ followed by immediate heating with a rate of $10 \mathrm{~K} \mathrm{~min}^{-1}$ ).
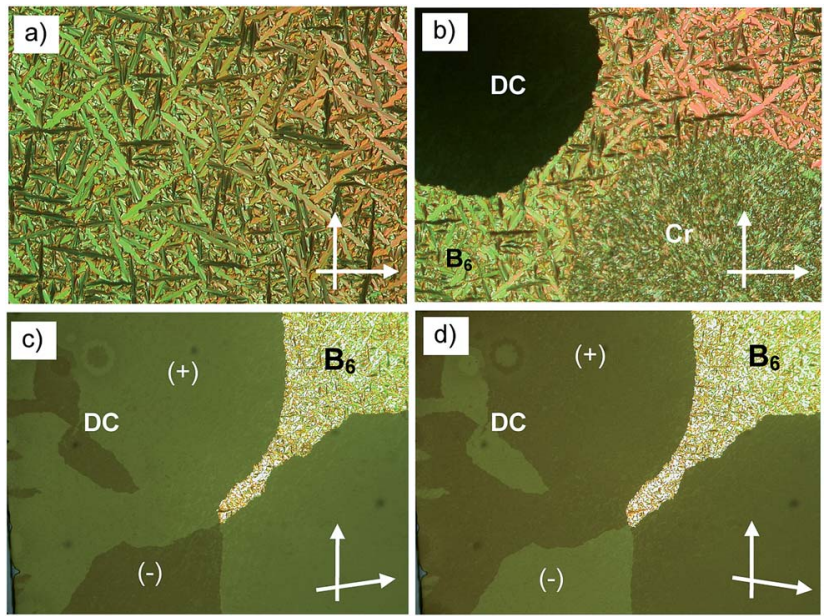

Fig. 3 Optical micrographs observed for A9 between crossed polarizers: (a) $\mathrm{B}_{6}$ phase at $T=86{ }^{\circ} \mathrm{C}$; (b) growth of the $\mathrm{DC}$ phase and the birefringent crystalline phase from the $B_{6}$ phase; (c) DC phase as grown from $\mathrm{B}_{6}\left(T=83^{\circ} \mathrm{C}\right.$, different region) after rotating one polarizer by $10^{\circ}$ from the crossed position in the anticlockwise direction and (d) in the clockwise direction, showing the chiral domains (on a larger field of view the stochastically distributed chiral domains occupy equal areas); the texture related to (c), (d), but between $90^{\circ}$ crossed polarizers is shown in Fig. S3b†; additional textures are shown in Fig. S3a, c and $\mathrm{d} . \dagger$

Compounds A10 and A12 easily crystallize on cooling or on reheating, but the DC phases of compounds with longer chains $(n=14-20)$ do not crystallize, once the DC phase is formed, as 

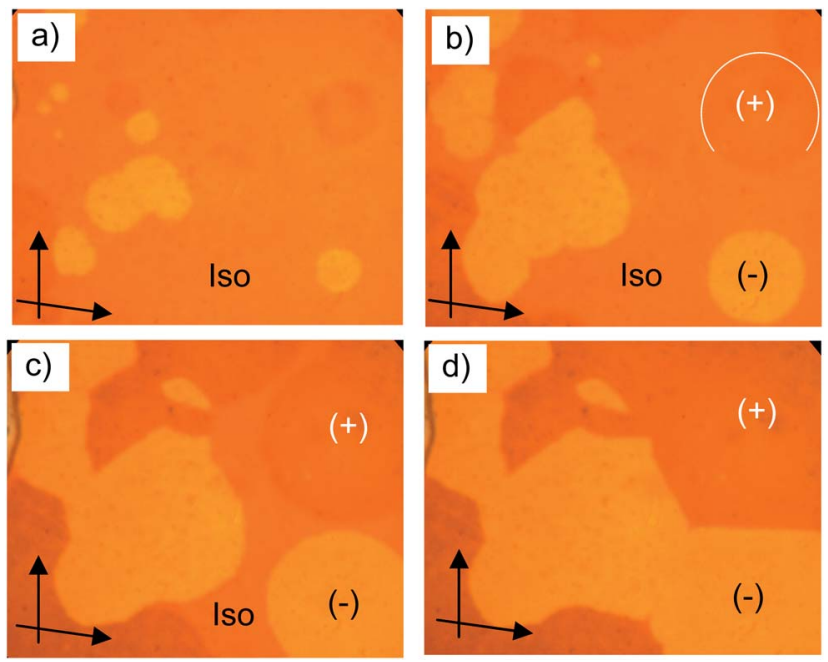

Fig. $4 a-d)$ Growth of the circular chiral domains of the DC phase of A10 upon cooling from the isotropic liquid state at $T=87^{\circ} \mathrm{C}$ as observed between slightly uncrossed polarizers (see arrows); the textures of the DC phase of A14 are shown in Fig. S4.†

shown in Fig. 5b for compound A18 as an example (for additional DSC curves, see Fig. S7 and S8). In the case of the long chain compound $\mathbf{A 2 0}$ a different behaviour is observed which is discussed here in some more detail. For this compound there is a strong effect of the cooling rate on the phase sequence and the phase structure (see Fig. $5 \mathrm{c}$ and d). On cooling from the isotropic liquid phase with a low rate of $\leq 2 \mathrm{~K} \mathrm{~min}^{-1}$ (Fig. 5c, curve b) the DC phase is formed at $T=95{ }^{\circ} \mathrm{C}$ and it does not crystallize on further cooling, and on heating only a single peak is observed at $T=104{ }^{\circ} \mathrm{C}$ (Fig. 5c, curve a), similar to compounds A14-A18 (Fig. 5b). The transition enthalpy is $\sim 57 \mathrm{~kJ}$
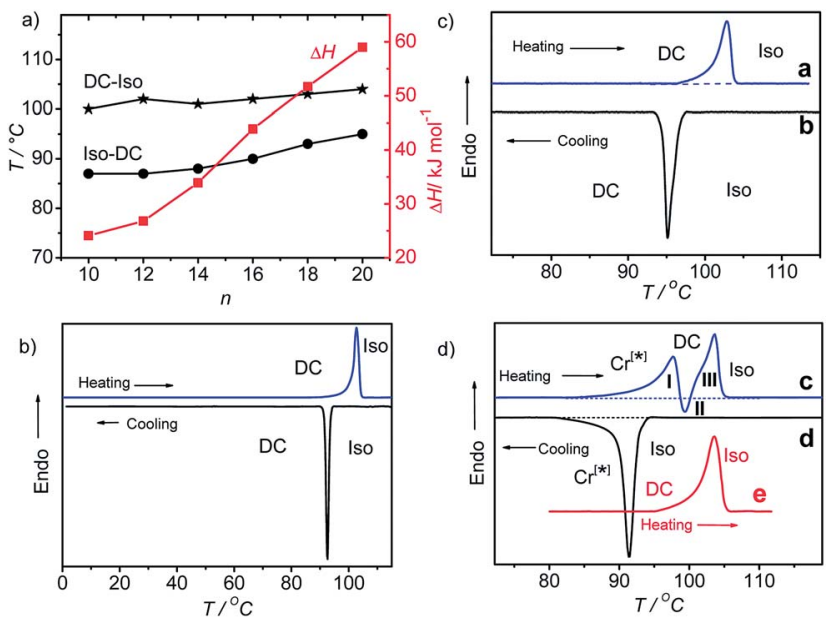

Fig. 5 a) Dependence of DC-Iso transition temperatures (on heating and cooling scans with $10 \mathrm{~K} \mathrm{~min}^{-1}$ ) and transition enthalpy values (on cooling from the isotropic liquid) of compounds A10-A20 on alkyl chain length $n$; $(b-d)$ DSC heating and cooling curves of (b) compound A18 at $10 \mathrm{~K} \mathrm{~min}^{-1}$, (c) compound $\mathrm{A} 20$ at $2 \mathrm{~K} \mathrm{~min}^{-1}$ and (d) compound A20 with a rate of $10 \mathrm{~K} \mathrm{~min}^{-1}$ (curves $\mathrm{c}$ and d); curve e was recorded after cooling with $2 \mathrm{~K} \mathrm{~min}^{-1}$. $\mathrm{mol}^{-1}$ on heating and $\sim 59 \mathrm{~kJ} \mathrm{~mol}^{-1}$ on cooling. However, on cooling with a faster rate of $\geq 5 \mathrm{~K} \mathrm{~min}^{-1}$ (Fig. 5d, curve d) a crystalline phase with a weakly birefringent spherulitic texture (see Fig. 6b) is formed at $T=92{ }^{\circ} \mathrm{C}$ and the transition enthalpy is now significantly larger, around $\sim 71 \mathrm{~kJ} \mathrm{~mol}^{-1}$ on cooling. ${ }^{44}$ The spherulitic texture (Fig. 6b) is similar to those found for columnar or (modulated) smectic LC phases, however, this phase is solid-like and does not flow on applying shear forces, and therefore, this is a crystalline phase.

Interestingly, also this crystalline phase is chiral and composed of domains with opposite handedness, i.e. dark and bright domains become visible if the polarizers are slightly uncrossed (see Fig. 6a and c), hence, this birefringent conglomerate phase is assigned as $\mathrm{Cr}^{[*]}$. Each of the spherulites appears to have uniform chirality, so it seems that the chirality is determined by each nucleus and is preserved through the growth process. ${ }^{45}$ On further cooling the $\mathrm{Cr}^{[*]}$ phase is retained and does not change down to room temperature, but on heating to $T=99{ }^{\circ} \mathrm{C}$ it transforms into the DC phase. At this transition the spherulitic texture becomes uniformly isotropic and the chirality as well as the sign of chirality in the distinct domains is retained (see Fig. 6e-g). This temperature corresponds to the position of the exotherm II in the heating curve $\mathrm{c}$ in Fig. $5 \mathrm{~d}$. The unusual shape of the DSC heating curve $\mathrm{c}$ is characterized by a significant tailing which rises up to a local maximum I, before it abruptly goes through an exothem II, and finally the peak maximum III is reached. This kind of DCS curve is always found for the heating curves after cooling the sample with rates $\geq 5 \mathrm{~K}$ $\min ^{-1}$, independent of the used heating rates (see Fig. S9 $\dagger$ ). The endothermic tailing I, starting at $T \sim 85{ }^{\circ} \mathrm{C}$, is interpreted as a result of a chain melting process which leads to a softening of the $\mathrm{Cr}^{[*]}$ phase. This obviously allows a denser packing (crystallization) of other molecular parts, giving rise to the exotherm II in the heating curve. At this temperature the $\mathrm{Cr}^{[*]}$ phase transforms into the DC phase, i.e. this transition is accompanied by a layer deformation which leads to the formation of the optically isotropic DC phase at $T=99{ }^{\circ} \mathrm{C}$. On further heating this DC phase melts into the isotropic liquid at the endothermic peak III at $T=104{ }^{\circ} \mathrm{C}$. Once formed (either on cooling the preformed DC phase or on slow cooling from the isotropic liquid sate), the DC phase is stable and it is retained down to room temperature; only a single peak at $T=104{ }^{\circ} \mathrm{C}$ is observed on heating (curve e in Fig. 5d). Even after storage at room temperature for more than 8 weeks the same transition temperatures and enthalpies were obtained. The persistence of the DC phases might be the result of the freezing of disordered alkyl chain segments into an immobilized, probably a glassy state, which, once formed, inhibits the transformation into the chiral $\mathrm{Cr}^{[*]}$ phase or any other crystalline phase.

Compound $\mathbf{A 2 2}$ with the longest chains is a crystalline solid with a melting point at $T=105{ }^{\circ} \mathrm{C}$. No formation of a DC phase could be detected at any cooling rate. Also in this case the crystalline phase formed on cooling consists of a conglomerate of chiral crystals (see Fig. S5 $\dagger$ ), though the chiral domains cannot be observed with the same clarity as for A20, because the birefringence is higher and no uniform texture is obtained. In the following focus is on the DC phases of compounds A10-A20. 

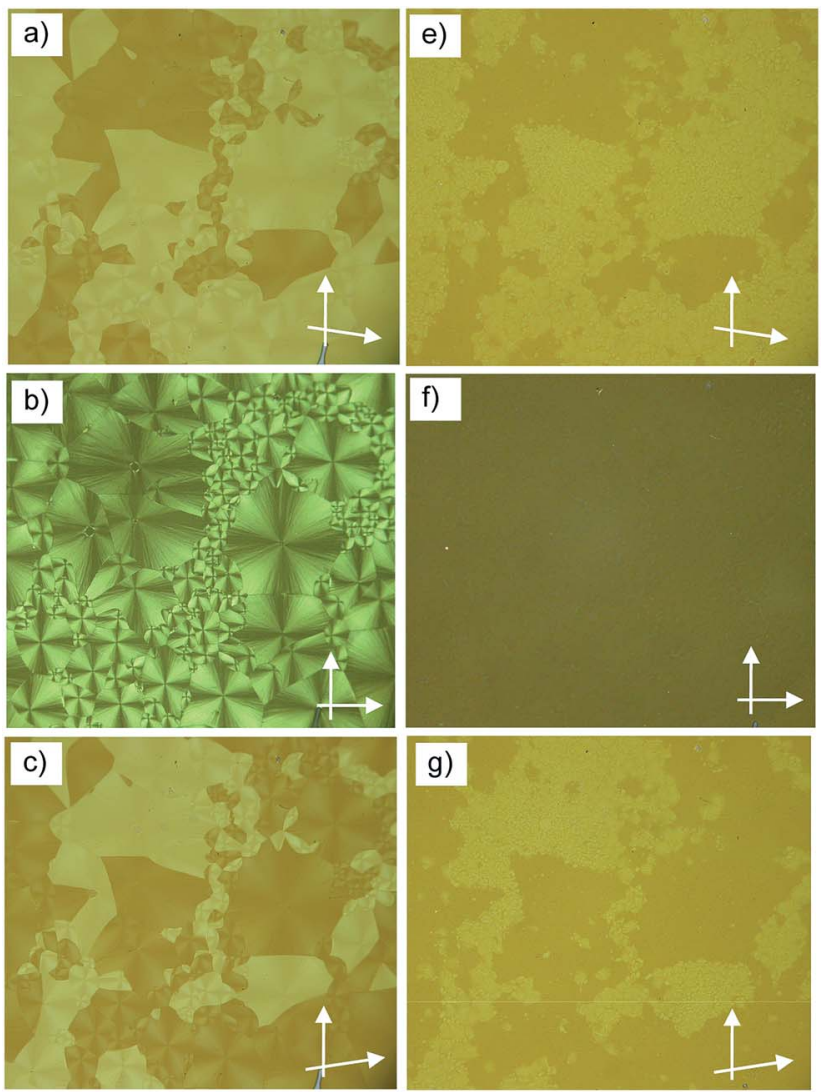

d)
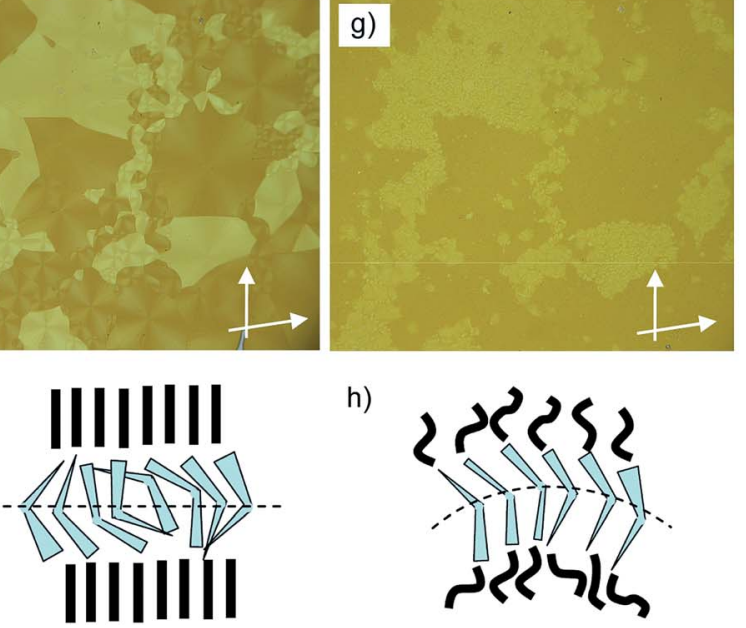

h)

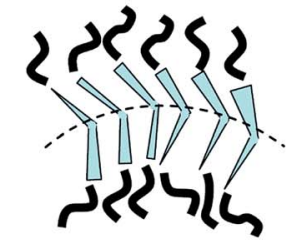

Fig. 6 Textures of compound A20 as observed between crossed and slightly uncrossed polarizers. (a-c) $\mathrm{Cr}^{[*]}$ phase at $T=93^{\circ} \mathrm{C}$ as obtained upon cooling with a rate of $5 \mathrm{~K} \mathrm{~min}^{-1}$ and $(\mathrm{e}-\mathrm{g}) \mathrm{DC}$ phase as obtained on heating to $100{ }^{\circ} \mathrm{C}$; ( $b$ and $f$ ) between crossed polarizers and ( $a$ and e) between slightly uncrossed polarizers with the analyzer rotated $8^{\circ}$ clockwise and (c and g) rotated $8^{\circ}$ anticlockwise; ( $d$ and h) show models of the molecular organization; (d) in the $\mathrm{Cr}^{[*]}$ phase the alkyl chains are fully crystallized, the aromatics are more disordered and have a stronger helical twist than in the DC phase; $(h)$ in the DC phase where the chains are disordered, allowing a denser and more ordered packing of the aromatic cores ("core crystallization"); this leads to a reduced molecular twist (reduced optical activity) and a stronger layer deformation, giving rise to optical uniaxiality.

3.4.2 Electrooptical investigations of the DC phases. In electrooptical experiments no current peak could be observed in the DC phases and also no birefringence is induced under an applied triangular wave voltage up to $200 \mathrm{~V}_{\mathrm{pp}}$ in a $6 \mu \mathrm{m}$ ITO cell. These features are similar to those known for soft crystalline HNF phases ( $B_{4}$ phases) and distinct from most fluid sponge phases.

3.4.3 Investigation of the DC phases by XRD. XRD investigations of $\mathbf{A 1 4}$ in the DC phase (see Fig. 7) indicate an intense layer reflection with its weak second to fifth order harmonic in the small and medium angle region $\left(d=4.47 \mathrm{~nm}, T=70^{\circ} \mathrm{C}\right)$. No alignment could be achieved and therefore in the 2D patterns, all scattering form closed rings with uniform intensity distribution (see Fig. 7 and S13-S17†). This is due to the disordered meso-scale structure, which is an inherent feature of all DC phases and leads to their optically isotropic appearance as well as to a broadening of all XRD reflections. The $2 \theta$ scans of the other compounds An are collated in Fig. 8.

In all cases the $d$-value is significantly larger than $L_{\mathrm{mol}} / 2$, but also smaller than the single molecular length, indicating a tilted monolayer-like organization of the molecules in the DC phases. The $d$-value of the layer reflection grows, as expected, with rising molecular length (Fig. 9a). The ratio $d / L_{\text {mol }}$ is $\sim 0.73-0.75$ for all investigated compounds which would, according to $d / L_{\mathrm{mol}}=$ $\cos \beta$, lead to a tilt angle around $40^{\circ} .^{46}$ This relatively large difference between $d$ and $L_{\text {mol }}$ distinguishes these DC phases from the previously reported HNF phases where $d$ is usually close to the molecular length. ${ }^{16,17}$

a)

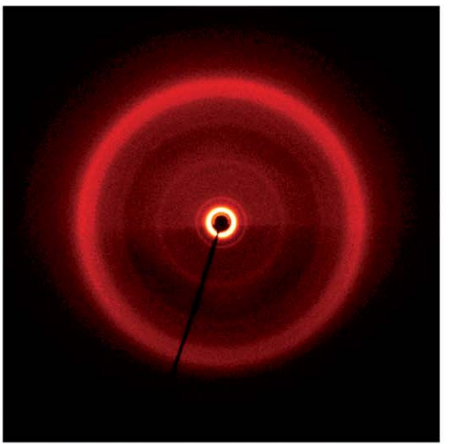

b)

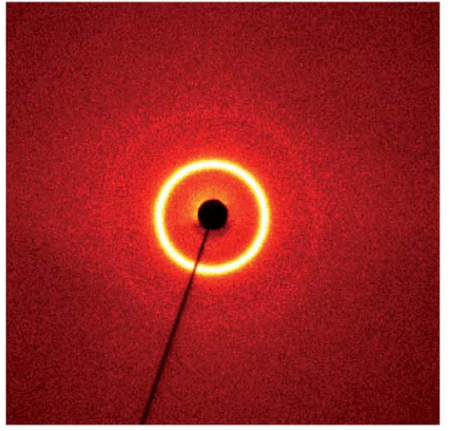

C)

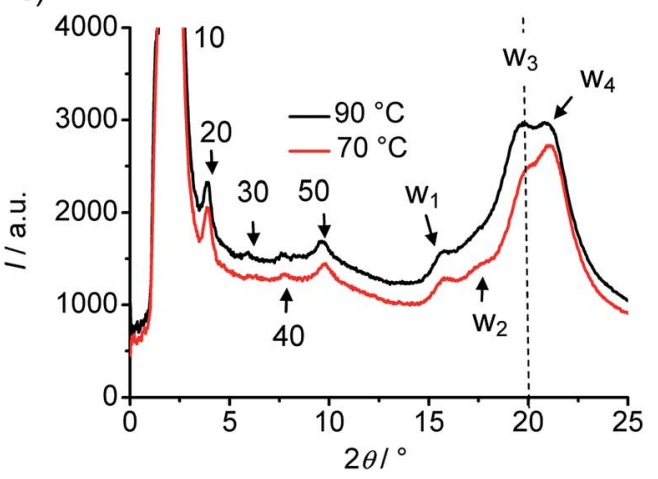

Fig. 7 XRD pattern of the DC phase of compound $A 14$ at $T=70^{\circ} \mathrm{C}$, (a) complete diffraction pattern, (b) small angle region and (c) $2 \theta$-scans at $T=70^{\circ} \mathrm{C}$ and $T=90^{\circ} \mathrm{C}$. 
In the medium angle region of the diffraction patterns of compounds A14-A20 there are additional distinct scattering maxima on top of a broad diffuse scattering covering the range between $2 \theta=5^{\circ}$ and $2 \theta=15^{\circ}$ (see Fig. 8), only for A10 exclusively the diffuse scattering could be observed. These reflections can be indexed as higher harmonics of the layer reflection (see Fig. 7c), as also found for the HNF phases. In the wide angle range there is a broad feature which could be fitted to 4 maxima $\left(\mathrm{w}_{1}-\mathrm{w}_{4}\right)$ in the $2 \theta$ range between 19 and $21^{\circ}$ (see Fig. $7 \mathrm{c}$ ). This pattern excludes fluid sponge phases, showing exclusively a very diffuse wide angle scattering besides the layer reflection. However, it is also distinct from the typical patterns of HNF phases ( $B_{4}$ phases), where the wide angle reflections have other positions and appear as significantly sharper separate peaks. ${ }^{9,20,21}$

With growing chain length the intensity of the second harmonics of the small angle scattering decreases and it has completely disappeared for compound A18 (Fig. 8), whereas the (50) and (40) reflections increase in intensity, most probably due to the changing electron density modulation resulting from the changing thickness of the aliphatic layers and other structural modifications. There is also a nearly continuous change of the positions of the wide angle scattering (Fig. 8 and 9), indicating continuous structural transformations depending on the chain lengths. An indexing of the wide angle diffraction patterns was not attempted, because of the limited number and the diffuse character of the reflections. Due to the overlapping of several scattering maxima the precise assignment of the positions of the maxima is difficult and the presence of additional scattering in this region cannot be excluded. In any case, the scattering in this region should result from the packing of the crystallized (mainly aromatic) segments on a $2 \mathrm{D}$ in-plane lattice. The significant line broadening is thought to be due to the limited correlation length of the crystalline micro-domains.

Major changes can be observed for the scattering $\mathrm{w}_{3}$ occurring around $2 \theta \sim 19-20^{\circ}$ which decreases in intensity (compare Fig. 8a-e) and is shifted to smaller $d$-values (see Fig. 9b) from $\mathbf{A 1 4}$ to A20. Based on its $d$-value in the range between 0.46 and $0.43 \mathrm{~nm}$ and its strong intensity dependence on temperature (see discussions below) it is thought that this scattering is most likely due to the mean distance between less ordered (not crystallized) segments of the alkyl chains. The observation that with increasing chain length the position of $\mathrm{w}_{3}$ is shifted to smaller $d$-values would be in line with a denser chain packing for longer chains.

The temperature effect on the XRD pattern of compound $\mathbf{A 1 4}$ in the DC phase is shown in Fig. 7c. There is no significant influence on the intensities and positions of the scattering
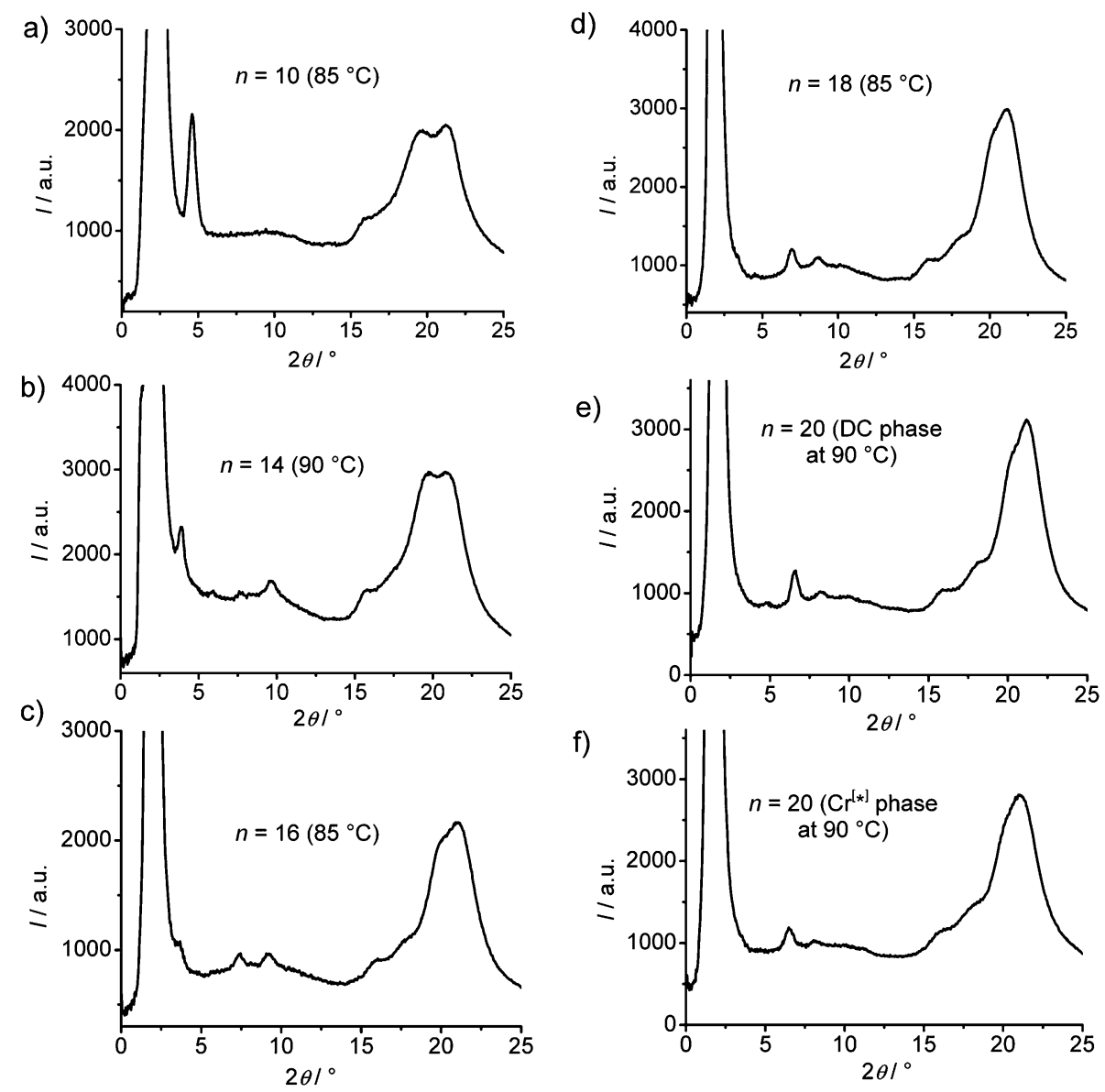

Fig. 8 Comparison of $2 \theta$-scans of the XRD patterns at the indicated temperatures for (a) A10, (b) A14, (c) A16, (d) A18 and (e) A20 in the DC phase (cooling rate $0.5 \mathrm{~K} \mathrm{~min}^{-1}$ in all cases) and (f) $\mathrm{A} 20$ in the $\mathrm{Cr}^{[*]}$ phase (after cooling with rate $10 \mathrm{~K} \mathrm{~min}^{-1}$ ). 
a)

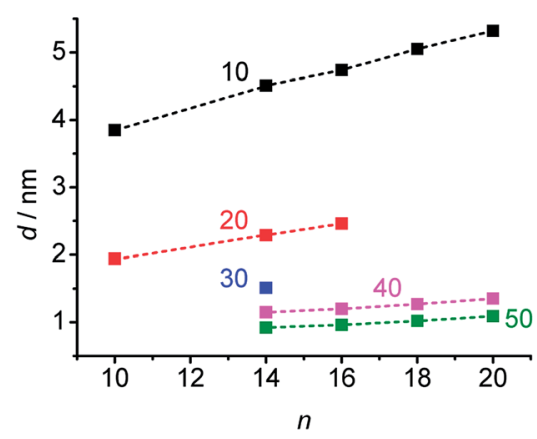

b)

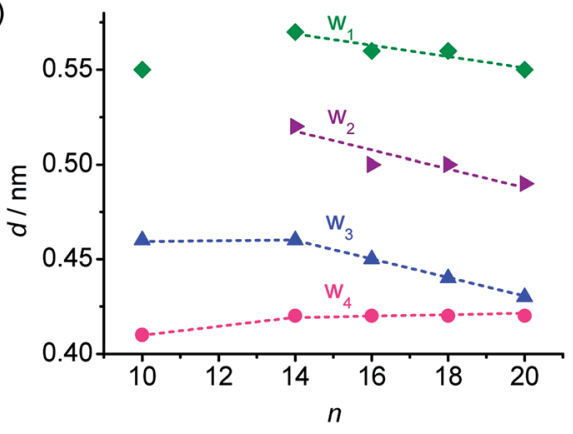

Fig. 9 Dependence of the XRD reflex position in the DC phases of compounds A10-A20 on chain length, (a) $d$-values of the layer reflections with the observed higher harmonics and (b) wide angle scattering maxima, the assignment of the reflections is shown in Fig. 7c, see also Fig. S13-S17.†

maxima with exception of $\mathrm{w}_{3}$ which is strongly reduced at decreased temperature, though its position is retained. Reducing the temperature has obviously a similar effect on the intensity of this scattering like increasing the alkyl chain length. This supports the assumption that this scattering maximum does not belong to the $2 \mathrm{D}$ in-plane lattice and could be attributed to the mean distance between the disordered alkyl chain segments. The fraction of the more disordered alkyl chain segments becomes smaller as temperature is reduced and as the alkyl chain length is increased, because longer chains provide a higher tendency for chain crystallization, as mentioned above. This corresponds with the observed strong rise of the DC-Iso transition enthalpy from $24.1 \mathrm{~kJ} \mathrm{~mol}^{-1}$ for $\mathbf{A} / \mathbf{1 0}$ to $59 \mathrm{~kJ} \mathrm{~mol}^{-1}$ for $\mathbf{A} / \mathbf{2 0}$ (see Table 1 and Fig. $5 \mathrm{a}$; values on heating). In line with increasing chain crystallization by chain elongation, the optically isotropic DC phase of compound A20 is in competition with a low birefringent crystalline conglomerate phase $\mathrm{Cr}^{[*]}$ and exclusively a $\mathrm{Cr}^{[*]}$ phase is formed by $\mathbf{A 2 2}$ with the longest chains.

For compound $\mathbf{A 2 0}$ the XRD patterns were recorded at the same temperature $\left(T=90{ }^{\circ} \mathrm{C}\right)$ after slow cooling $\left(0.5 \mathrm{~K} \mathrm{~min}^{-1}\right.$ Fig. 8e) in the DC phase as well as after fast cooling $\left(10 \mathrm{~K} \mathrm{~min}^{-1}\right.$ Fig. 8f) in the $\mathrm{Cr}^{[*]}$ phase. Surprisingly, the two XRD patterns look very similar, only all scattering appear to be a bit broader and have slightly lower intensity in the birefringent $\mathrm{Cr}^{[*]}$ phase, though the sample and exposure time were identical. This is reproducibly observed and would suggest a reduced local order in the $\mathrm{Cr}^{[*]}$ phase compared to the DC phase. This is in line with the suggested core crystallization as origin of the exotherm (II) occurring on heating at the transition from the birefringent $\mathrm{Cr}^{[*]}$ phase to the optically isotropic DC phase (see curve $\mathrm{c}$ in Fig. 5d). Because chirality is observed in the birefringent $\mathrm{Cr}^{[*]}$ phase as well as in the isotropic DC phase, the aromatic cores should in both phases adopt chiral helical conformations with uniform helix sense, which is opposite in the distinct chiral domains. At the $\mathrm{Cr}^{[*]}$-DC transition the contrast between the dark and bright domains decreases (compare Fig. 6a, e and c, g). This reduced optical activity indicates a reduction of the helical twist of the molecular conformations at the transition from the crystalline to the DC phase. Molecular entities with uniform helix sense cannot be densely packed in nondistorted layers and thus induce twist and curvature. This distortion increases with growing packing density of the helical entities, and therefore the denser core packing leads to a stronger layer deformation force, giving rise to the formation of the optically isotropic DC phase. The birefringent $\mathrm{Cr}^{[*]}$ phase, formed on rapid cooling appears to be dominated by optimized alkyl chain packing (chain crystallization), which allows a non-twisted lamellar or modulated lamellar organization of the molecules, but without optimized core-packing. The aromatic cores remain in a strongly twisted helical conformation, leading to a high optical activity, but the strong molecular twist also leads to a disruption of the aromatic layers into smaller domains (see Fig. 6d). Upon heating the $\mathrm{Cr}^{[*]}$ phase, the alkyl chain order decreases and a growing fraction of these chains becomes disordered. This allows a denser core packing, simultaneously leading to a reduced helicity of the molecular conformations (reduced optical activity) and, giving rise to a strong layer distortion and formation of the DC phase with an increased alkyl chain disorder. This means that the isotropic DC phases are the result of the optimization of core packing and represent disordered versions of the birefringent crystalline conglomerates $\left(\mathrm{Cr}^{[*]}\right.$ phases), providing improved alkyl chain packing. With rising alkyl chain length the chain crystallization becomes increasingly more important. For compound A20 formation of the optical isotropic DC phase can still be achieved by using sufficiently slow cooling rates, so that the slow core crystallization can take place and determine the structure, leading to the DC phase. On fast cooling, however, densest core packing obviously cannot be achieved and the fast chain crystallization leads to a non-twisted lamellar organization, giving rise to the birefringent conglomerate phase $\mathrm{Cr}^{[*]}$ with reduced core order and enhanced optical activity. For compound A22 chain crystallization dominates at all cooling rates, and hence, exclusively a crystalline phase is formed.

Low birefringent crystalline conglomerate phases were also observed for compounds A14-A18, but for these compounds very high cooling rates $\left(\gg 20 \mathrm{~K} \mathrm{~min}^{-1}\right)$ are required for their formation and there is apparently always a coexistence of these birefringent $\mathrm{Cr}^{[*]}$ phases with the isotropic DC phases, which makes the investigations difficult. Fig. 10 shows representative textures and DSC curves as obtained for compound A16 after rapid cooling ( $30 \mathrm{~K} \mathrm{~min}^{-1}$ for the texture and $50 \mathrm{~K} \mathrm{~min}^{-1}$ before recording the DSC trace a). For these compounds core crystallization is sufficiently fast compared to alkyl chain 
crystallization and therefore DC phases can be observed for moderate cooling rates. The $\mathrm{Cr}^{[*]}$ phases are absent for all shorter homologues starting with A12, which have the smallest contribution of alkyl chain crystallization to the total transition enthalpy value (Fig. 5a); here self-assembly is dominated by optimized core packing, which leads to DC phase formation.

3.4.4 Molecular conformation and structure property relations. DFT calculations of the model compound A1 with $n=1$ (Gaussian 09 package, B3LYP functional and the LAN L2 DZ basis set) indicate a bent and helically twisted chiral molecular conformation as the minimum energy conformation shown in Fig. 11. The 4-methyl group at the resorcinol core unit does not induce a significant deviation from the $120^{\circ}$ bending angle between the two azobenzene wings. Also, the azobenzene units themselves are linear and the benzene rings in these wings as well as the $\mathrm{C}=\mathrm{O}$ groups are nearly coplanar. However, the methyl group at the 4-position at the resorcinol core induces a significant twist of the adjacent carboxyl group together with the coplanar azobenzene wing out of the plane of the resorcinol unit by $72.4^{\circ}$, which is much larger than that of the azobenzene wings adjacent to H-6 $\left(53.6^{\circ}\right)$. This strong twist leads to an overall helical molecular conformation and this is assumed to be responsible for a high tendency for chiral segregation and distorted packing in layers. Though the understanding of the general structure property relations with respect to formation of DC phases is still at the infancy it appears that the presence of relatively flat and rigid aromatic $\pi$-systems, as provided by azobenzenes and to some extent also by Schiff base units is favorable for formation of soft crystalline DC phases. So, it
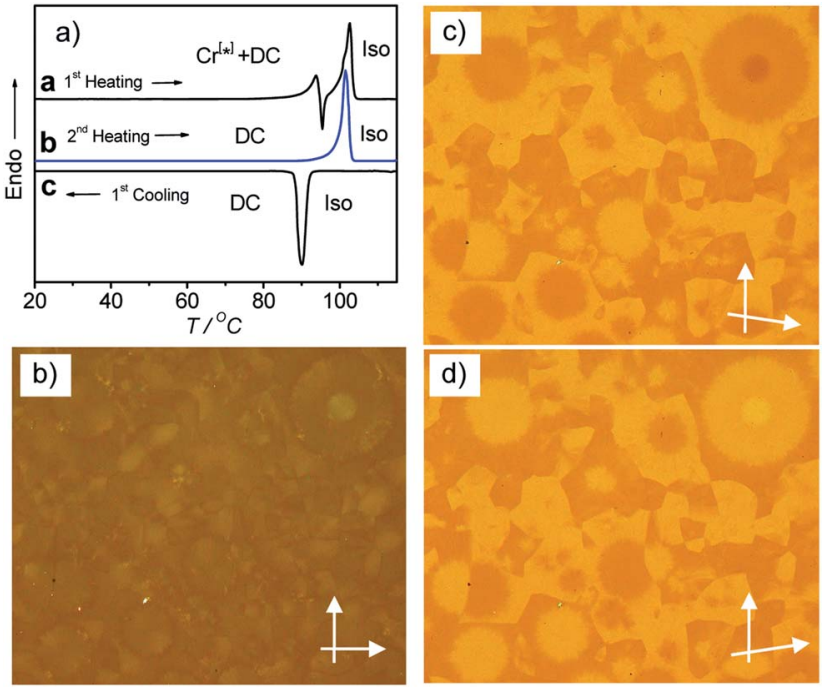

Fig. 10 Compound A16: (a) DSC traces $\left(10 \mathrm{~K} \mathrm{~min}^{-1}\right)$ : curve a, heating after previous cooling with $50 \mathrm{~K} \mathrm{~min}^{-1}$; curves $\mathrm{b}$ and $\mathrm{c}$, heating/cooling with $10 \mathrm{~K} \mathrm{~min}^{-1}$; (b) low birefringent texture of the $\mathrm{Cr}^{[*]}$ phase as obtained after fast cooling (30 K min ${ }^{-1}$ ); (c) same texture between slightly uncrossed polarizers and (d) after reversal of the direction of one polarizer, indicating the presence of a chiral conglomerate; remarkable is the presence of a domain with higher contrast in the center of the circular domain at the top right; probably, the birefringent textures develop as surface layers and in these regions goes through the complete sample. a)

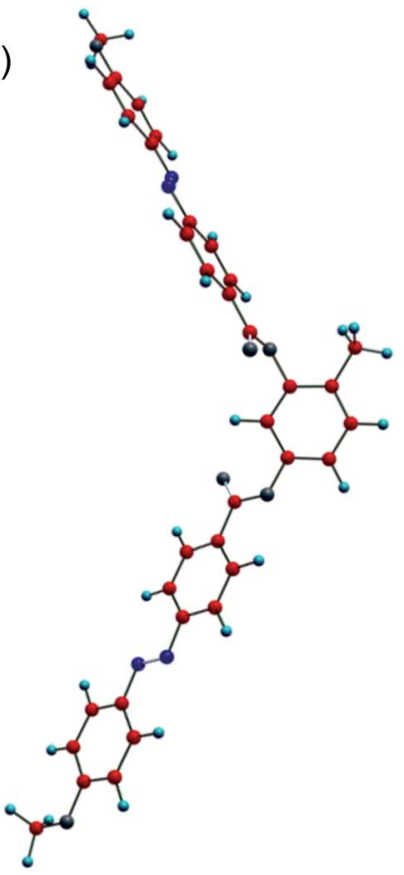

b)

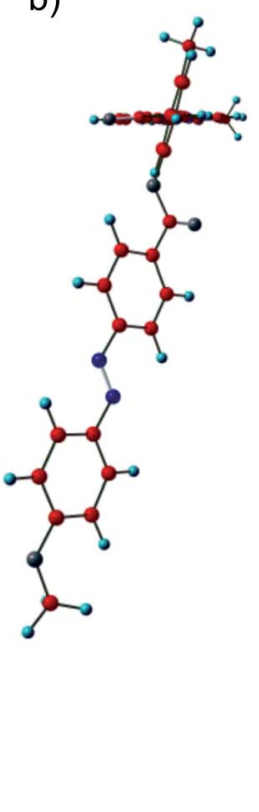

Fig. 11 Energy minimized molecular conformer of the model compound A1 ( $n=1)$ as observed under two distinct perspectives (a) perpendicular to the bending plane and (b) along the azobenzene wing adjacent to the methyl group.

appears that $\pi$-stacking favours DC phase formation. In the case of the azobenzenes the presence of an additional relatively bulky substituent, such as I, Br or $\mathrm{CH}_{3}$ seems to be required, probably by providing a stronger molecular twist. In contrast, formation of LC sponge type DC phases is favoured for bentcore compounds with more flexible phenylbenzoate wings and having long and flexible or bulky end groups at the termini. ${ }^{8}$ However, final conclusions cannot be drawn here and require further investigations.

3.4.5 Investigation of mixtures with 5 -CB. It is known that HNF phases can be diluted by nematic LC hosts to a high degree $(>95 \%)$ without the loss of the chirality. ${ }^{47}$ This is a direct consequence of the helical nanofilament structure of these phases, allowing a swelling of the filaments by the nematic LC and transfer of chirality from the nanofilaments to the nematic LC. This effect is not observed for the sponge type DC phases formed by distorted fluid smectic phases. Therefore, investigation of mixtures with 5-CB could provide additional information concerning the microstructure of the DC phases of compounds An. The $1: 1$ mixture of A14 with $4^{\prime}$-n-pentyl-4-cyanobiphenyl (5-CB) does not show any DC phase. On heating this mixture only a direct transition from the crystalline material to the isotropic liquid state occurs at $85^{\circ} \mathrm{C}$ which is below the DC-Iso transition temperature of pure $\mathbf{A 1 4}\left(T=101^{\circ} \mathrm{C}\right)$. On cooling this mixture a transition from the isotropic liquid to the nematic phase takes place at $T \sim 54{ }^{\circ} \mathrm{C}$, but no chiral domains can be observed. The nematic phase rapidly crystallizes with formation of a highly birefringent crystalline phase at $T \sim 53{ }^{\circ} \mathrm{C}$ (see Table 2 and Fig. S19†).

The longer compounds A16-A20 behave differently; for the 1:1 mixtures the DC phases were retained and their 
temperature ranges increase with growing chain length (Table 2 and Fig. S20†). However, at only slightly higher 5-CB concentration, as for example, in the $4: 6$ mixtures of compounds A16A20 with 5-CB the chiral DC phase is lost and instead a heterogenous mixture is obtained indicating that the amount of 5-CB which can be mixed into the DC phases of compounds An is strongly limited. So, compared with the HNF phases, the DC phases of compounds An can only be retained if the alkyl chains are sufficiently long, but also in this case much less 5-CB is tolerated. These observations, in conjunction with the XRD studies, confirm that the DC phases of compounds An should be different from the classical HNF phases. It appears that these phases are formed by smaller nano-domains instead of long helical filaments, in line with the results discussed in the previous sections. Because no extended filaments are formed, no gel-like networks of these fibers are possible and therefore these compounds can take up only a limited amount of 5-CB, which is directly incorporated between the bent-core molecules thus reducing the stability of the DC phases.

Mixing the longest homologue A22, which does not show any DC phase, with 5-CB in 1:1 ratio induces a DC phase as an enantiotropic phase between $T=59^{\circ} \mathrm{C}$ and $87^{\circ} \mathrm{C}$ (see Fig. S21 $\dagger$ ). This shows that 5 -CB can reduce the chain crystallization and thus allow the formation of the DC phase even if the pure compound itself does not show any DC phase. However, no DC phase can be induced in the fluorinated compounds $\mathrm{B} \boldsymbol{n}(\mathrm{X}=\mathrm{F}$, $1: 1$ mixtures with 5 -CB) that show polar smectic phases and are discussed in Section 3.5.

\subsection{Polar and non-polar smectic phases formed by compounds $\mathrm{B} n-\mathrm{D} n$ with additional peripheral substituents}

In order to investigate the effect of introducing a lateral substitution on the outer two benzene rings in the periphery of the aromatic core of the bent-core liquid crystals $\mathbf{A} n$, related molecules Bn, C14 and D14 were synthesized (Scheme 2). In the series of compounds $\mathbf{B} \boldsymbol{n}$ with $\mathrm{X}=\mathrm{F}$ all compounds show the same type of mesophase, irrespective of the chain length (see Table 1). As an example, on heating B14 in a homeotropic cell a schlieren texture is observed at $T=90{ }^{\circ} \mathrm{C}$ (see Fig. S6a $\dagger$ ) indicating the presence of a SmC phase. The relatively high transition enthalpy $\left(\Delta H \sim 12.8 \mathrm{~kJ} \mathrm{~mol}^{-1}\right)$ is in the range as usually found for polar SmC phases (for representative DSC traces, see

Table 2 Phase transition temperatures and mesophase types of $1: 1$ mixtures of 5-CB and compounds A14-A22 and B14 ${ }^{a}$

\begin{tabular}{lll}
\hline Mixture & Heating $T /{ }^{\circ} \mathrm{C}$ & Cooling $T /{ }^{\circ} \mathrm{C}$ \\
\hline A14-5-CB & $\mathrm{Cr}_{1} 39 \mathrm{Cr}_{2}$ 85 Iso & Iso $54 \mathrm{~N} 53 \mathrm{Cr}$ \\
A16-5-CB & $\mathrm{Cr} 64 \mathrm{DC} 73$ Iso & Iso 66 DC \\
A18-5-CB & DC 77 Iso & Iso 72 DC \\
$\mathbf{A 2 0}-5-\mathrm{CB}$ & $\mathrm{DC} 80$ Iso & Iso 78 DC \\
$\mathbf{A 2 2}-5-\mathrm{CB}$ & $\mathrm{Cr}^{[*]} 59 \mathrm{DC}$ 87 Iso & Iso 80 DC $37 \mathrm{Cr}^{[*]}$ \\
$\mathbf{B 1 4}-5-\mathrm{CB}$ & $\mathrm{Cr} 63$ Iso & Iso 61 Cr
\end{tabular}

${ }^{a}$ Transition temperatures were taken from the observed textures using polarized optical microscopy; abbreviations: $\mathrm{N}=$ nematic phase, for other abbreviations please see Table 1.
Fig. S10†). The presence of two polarization reversal peaks in each half period of an applied triangular wave voltage $\left(160 \mathrm{~V}_{\mathrm{pp}}\right.$, see Fig. 12a) indicate an antiferroelectric switching process. The spontaneous polarization value was calculated to be $P_{\mathrm{s}}=650 \mathrm{nC}$ $\mathrm{cm}^{-2}$ at $85{ }^{\circ} \mathrm{C}$. On cooling the compound in a $6 \mu \mathrm{m}$ ITO coated cell under an external applied field circular domains are formed (Fig. 12c). At $0 \mathrm{~V}$ the position of the extinction crosses is parallel to the polarizers, indicating an anticlinic tilted $\operatorname{SmC}_{\mathrm{a}} \mathrm{P}_{\mathrm{A}}$ phase. Under an applied electric field the extinction crosses in the circular domains become inclined to the directions of the polarizers, indicating a field induced synclinic $\operatorname{SmC}_{\mathrm{S}} \mathrm{P}_{\mathrm{F}}$ phase. By changing the direction of the applied electric field three distinct states (see Fig. 12b-d) can be clearly observed confirming a tristable switching process by rotation on a cone. Based on these results it is concluded that this is a $\mathrm{B}_{2}$-type polar $\mathrm{SmC}$ phase with an anticlinic antiferroelectric $\mathrm{SmC}_{\mathrm{a}} \mathrm{P}_{\mathrm{A}}$ ground state structure.

Replacing the fluorine substituents in $\mathbf{B} \boldsymbol{n}$ by methyl groups (D14) leads to a monotropic SmC phase (for texture see Fig. S6b $\dagger$ ) without polar order, also indicated by the much smaller SmC-Iso transition enthalpy values $\left(0.9 \mathrm{~kJ} \mathrm{~mol}^{-1}\right)$ and the observation that no current peak could be observed up to a voltage of $200 \mathrm{~V}_{\mathrm{pp}}$ in a $6 \mu \mathrm{m}$ ITO cell. It appears that increasing the size of the peripheral substituents $\mathrm{X}$ reduces the packing density significantly, thus leading to strong reduction of mesophase stability in the order $\mathrm{H} \sim \mathrm{F}>\mathrm{CH}_{3}>\mathrm{Br}$, at first leading to a loss of polar order for $\mathrm{X}=\mathrm{CH}_{3}$ and finally to a complete
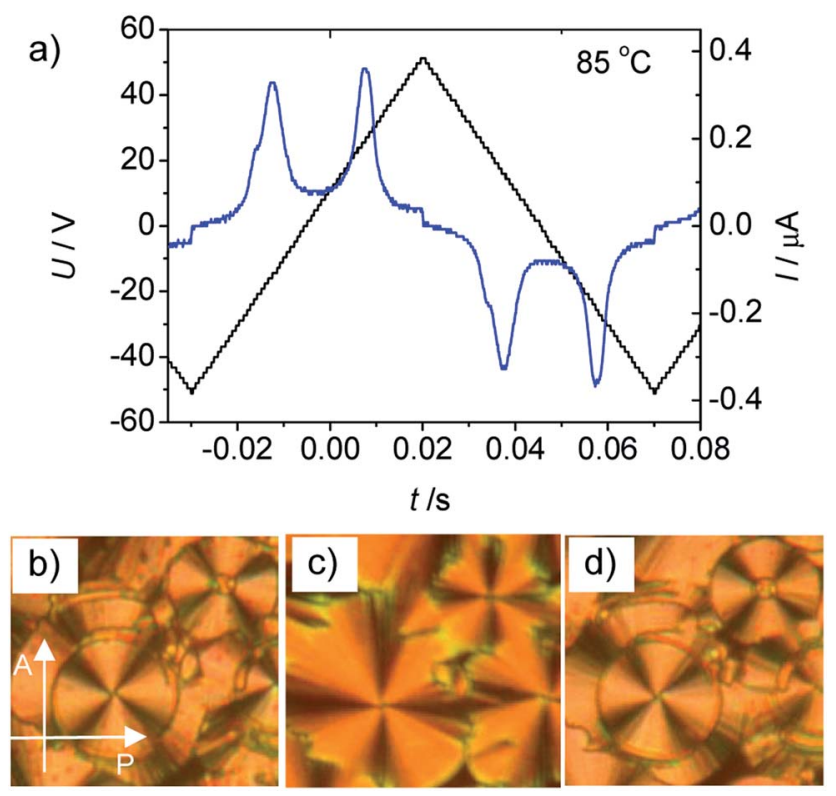

Fig. 12 Electrooptical investigation of compound B14. (a) Switching current response curve recorded by applying a triangular wave voltage $\left(160 \mathrm{~V}_{\mathrm{pp}}, 10 \mathrm{~Hz}, 5 \mathrm{k} \Omega\right.$ ) to a $6 \mu \mathrm{m}$ coated ITO cell with a homogeneous PI alignment layer at $85^{\circ} \mathrm{C}$ in the $\mathrm{SmC}_{\mathrm{a}} \mathrm{P}_{\mathrm{A}}$ phase; $(\mathrm{b}-\mathrm{d})$ optical textures as obtained at $T=79^{\circ} \mathrm{C}$ under an applied DC voltage between crossed polarizers (parallel rubbing), rubbing direction parallel to the polarizer, direction of the polarizers is shown in (b); (b) field induced $\mathrm{SmC}_{S} \mathrm{P}_{\mathrm{F}}$ state at $+10 \mathrm{~V}$, (c); $\mathrm{SmC}_{\mathrm{a}} \mathrm{P}_{\mathrm{A}}$ ground state after switching off the field $(0$ $\mathrm{V})$ and $(\mathrm{d})$ the field induced $\mathrm{SmC}_{\mathrm{S}} \mathrm{P}_{\mathrm{F}}$ state at $-10 \mathrm{~V}$. 
suppression of all mesophases for $\mathrm{X}=\mathrm{Br}$. As the electronegative $\mathrm{F}$ atoms increase the polarity of the core region, and hence increase the segregation of the core from the lipophilic alkyl chains, there is no significant mesophase destabilization or a slight stabilization if $\mathrm{H}$ is replaced by $\mathrm{F}$ (compare $\mathbf{A 1 4}$ and $\mathrm{B14}$ in Table 1). But nevertheless, chiral segregation is removed. The dominance of steric effects of $\mathrm{Br}$ and $\mathrm{CH}_{3}$ leads to the loss of polar order and to the lowest LC phase stability for these compounds.

\subsection{Effects of replacing the azo groups by ester groups}

Aiming to investigate the effects of replacing the azo linking groups in compounds A14 by ester groups, compounds E14, F14 and G14 were synthesized. As shown in Scheme 3, the mesophase exhibited by E14 is enantiotropic with a relatively wide LC range and much higher transition temperatures than found for A14. The texture of the LC phase (Fig. S6c †) is similar to those observed for modulated smectic phases of bent-core mesogens. ${ }^{48}$ On applying a triangular wave electric field of $160 \mathrm{~V}_{\mathrm{pp}}$ to E14 in a $6 \mu \mathrm{m}$ ITO cell, two polarization reversal peaks can be clearly observed in the switching current response curve (see Fig. S22 $\dagger$ ) indicating antiferroelectric switching. The spontaneous polarization value, $P_{\mathrm{s}}=310 \mathrm{nC} \mathrm{cm}{ }^{-2}$ at $120{ }^{\circ} \mathrm{C}$ is only about one half of that usually observed for $\mathrm{SmCP}_{\mathrm{A}}$ phases ( $\sim 600-800$ in the $B_{2}$ phases) and is in the typical range as observed for modulated $\mathrm{SmCP}_{\mathrm{A}}$ phases. By changing the direction of the applied electric field (Fig. S23†), no change in the texture could be observed, confirming that the switching process in this mesophase takes place by collective rotation around the long axis of the molecules. This mode of switching is also in line with a modulated structure of this $\mathrm{SmCP}_{\mathrm{A}}$ phase $\left(\mathrm{SmC} \tilde{\mathrm{C}}_{\mathrm{a}} \mathrm{P}_{\mathrm{A}}\right)$; for a nondistorted flat $\mathrm{SmC}_{\mathrm{a}} \mathrm{P}_{\mathrm{A}}$ phase a switching on a cone would be more likely.
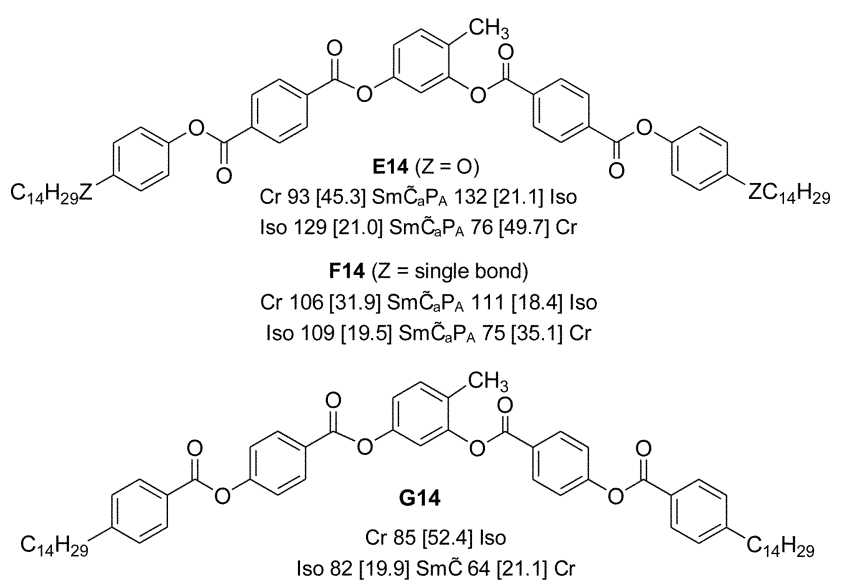

Scheme 3 Chemical structures of the synthesized 4-methylresorcinol based terephthalates E14, F14 and benzoate G14 with transition temperatures $\left(T /{ }^{\circ} \mathrm{C}\right)$ and corresponding enthalpies $\left(\Delta H / \mathrm{kJ} \mathrm{mol}^{-1}\right.$, given in square brackets) on heating (top lines) and cooling (bottom lines, both recorded at a rate of $10 \mathrm{~K} \mathrm{~min}^{-1}$ ); abbreviations: $\mathrm{Sm} \tilde{\mathrm{C}}_{\mathrm{a}} \mathrm{P}_{\mathrm{A}}=$ modulated antiferroelectric switching anticlinic SmC phase; Sm $\tilde{C}=$ non-switchable modulated SmC phase with synclinic tilt correlation, for other abbreviations, see Scheme 1 and Table 1; for DSC traces, see Fig. S11. $\uparrow$
In XRD measurements of compound E14 (Fig. S18†) several equally spaced sharp reflections can be found in the small angle region, indicating a lamellar structure with a $d$-value of $4.83 \mathrm{~nm}$. The diffuse scattering in the wide angle region shows four intensity maxima beside the equator, from which a tilt angle of the molecules of $\sim 28^{\circ}$ could be calculated. As the extinction crosses are approximately parallel to the polarizers (Fig. S6c $\dagger$ ) and an equal intensity of the wide angle scattering is found (Fig. S18a and $\mathrm{b} \dagger$ ) the tilt correlation should be anticlinic. Though there are indications of layer modulations or undulations from other experimental data, these are not visible in the XRD patterns. Either the modulation wavelength is very long, so that the layer reflections are not resolved into separate reflections, or the reflections with $h$ and $k \neq 0$ are too weak to be detected with the used XRD setup.

Replacing the terminal alkoxy chains in $\mathbf{E 1 4}$ by alkyl chains in compound F14 (see Scheme 3, for DSC traces see Fig. S11a $\dagger$ ) leads to a compound with about $20 \mathrm{~K}$ lower clearing temperature which can also be assigned as $\operatorname{SmC}_{\mathrm{a}} \mathrm{P}_{\mathrm{A}}$ based on the observed textures and measured $P_{\mathrm{S}}$ values $\left(P_{\mathrm{s}}=300 \mathrm{nC} \mathrm{cm}^{-2}\right.$ at $95{ }^{\circ} \mathrm{C}$, see Fig. S24 $\dagger$ ). The major difference between the two compounds is the inclination of the dark extinctions upon applying an electric field (Fig. S25†), indicating that the switching process in this case takes place on a cone; so probably the modulation wavelength of F14 is larger than for E14.

Inverting the direction of the terminal ester group in compound G14 (see Scheme 3) further reduces the transition temperatures, which are now similar to those of the azobenzene derivative $\mathbf{A 1 4}$ (for DSC traces see Fig. S11b $\dagger$ ). Also in this case the texture is similar to those of some modulated smectic phases (Fig. S6d $\dagger$ ). The position of the extinction crosses is inclined with the orientation of the polarizers and thus indicates a synclinic tilted organization of the molecules. In electrooptic studies $\left(160 \mathrm{~V}_{\mathrm{pp}}\right.$ in a $6 \mu \mathrm{m}$ ITO cell) no current response can be detected. This might be due to a shorter modulation wavelength than in the case of E14, which is known to suppress polar switching or would require very high voltages. Also the observation of a uniform synclinic tilt would be in line with a

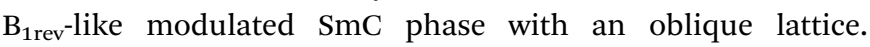
However, it was not possible to further confirm the proposed phase structure by XRD due to the rapid crystallization. Overall, replacing the azobenzene wings by terephthalates $(\mathbf{E 1 4}, \mathbf{F 1 4})$ or benzoates (G14) removes the DC phases and leads to polar and apolar smectic phases with a significant tendency for layer modulation or undulation.

\section{Conclusions and summary}

New bent-core liquid crystalline materials combining 4-methylresorcinol with azobenzene wings were synthesized and investigated. The short homologues $(n=6-8)$ exhibit intercalated smectic phases ( $\mathrm{B}_{6}$ phases) which upon increasing the chain length $(n=9-20)$ convert to DC phases and for the longest homologue $(n=22)$ only a crystalline phase was observed. For compound $\mathbf{A 2 0}$ formation of the optically isotropic DC phase is in competition with formation of a low birefringent crystalline conglomerate $\left(\mathrm{Cr}^{[*]}\right)$ and the observed phase type is strongly 
dependent on the cooling rate. It appears that formation of the $\mathrm{Cr}^{[*]}$ phase is favored by chain crystallization, whereas in the isotropic DC phases core crystallization is dominating. Based on the XRD patterns and high viscosity the DC phases of compounds An belong to the soft crystalline DC phases, but they are distinct from the previously reported $\mathrm{B}_{4}$-type $\mathrm{HNF}$ phases by the absence of extended filaments as indicated by the results of their mixtures with 5-CB.

Introduction of additional substituents at the outer rings of the bent-core molecules $\mathbf{A} \boldsymbol{n}$ removes the DC phases and replaces them first by polar smectic phases $\left(\mathrm{X}=\mathrm{F}, \mathrm{SmC}_{\mathrm{a}} \mathrm{P}_{\mathrm{A}}\right)$. Upon further enlargement of these substituents $\left(\mathrm{X}=\mathrm{CH}_{3}\right)$ also polar order is removed, yielding a non-polar SmC phase which is then removed for the compound with the largest substituent $\mathrm{X}=\mathrm{Br}$. Replacing the azo groups by ester groups in the related terephthalates or benzoates also removes the DC phases and leads to different types of modulated SmC phases which in most cases show polar switching.

Overall, new modifications of isotropic as well as birefringent conglomerate phases were observed and the relationship between molecular structure and formation of these phases was identified. It appears that the azobenzene unit is a specially powerful tool for introducing new types of chiral conglomerate phases, distinct from the typical $\mathrm{B}_{4}$ type phases found for benzylidene imines. There seems to be a whole zoo of different types of these DC phases, ranging from the fluid $\mathrm{B}_{2}$-like sponge phases to several distinct types of soft crystalline phases, including modulated subtypes; ${ }^{49-51}$ obviously only a small fraction of the potential structures has been explored yet. Moreover, the possibilities provided by introduction of the photoisomerizable azobenzene units into BCLC forming DC phases could lead to interesting perspectives for chirality switching and phase modulation, leading to unique and potentially useful multifunctional chiral materials for application in chiral discrimination of chiral physical forces and molecular species ${ }^{22}$ and as non-centrosymmetric materials.

\section{Acknowledgements}

M. Alaasar is grateful to the Alexander von Humboldt Foundation for the research fellowship at the Martin-Luther University Halle-Wittenberg, Germany.

\section{References}

1 T. Sekine, T. Niori, J. Watanabe, T. Furukawa, S. W. Choi and H. Takezoe, J. Mater. Chem., 1997, 7, 1307.

2 (a) R. A. Reddy and C. Tschierske, J. Mater. Chem., 2006, 16, 907; (b) H. Takezoe and Y. Takanishi, Jpn. J. Appl. Phys., Part 1, 2006, 45, 597; (c) G. Pelzl, S. Diele and W. Weissflog, Adv. Mater., 1999, 11, 707; (d) C. Tschierske, Angew. Chem., Int. Ed., 2013, 52, 8828; (e) V. Görtz and J. W. Goodby, Chem. Commun., 2005, 3262; (f) G. Pelzl and W. Weissflog, in Thermotropic Liquid Crystals, ed. A. Ramamoorthy, Springer, The Netherlands, 2007, pp. 58-83; $(g)$ I. Dierking, Angew. Chem., Int. Ed., 2010, 49, 29; $(h)$ A. Eremin and A. Jákli, Soft Matter, 2013, 9, 615.
3 D. R. Link, G. Natale, R. Shao, J. E. Maclennan, N. A. Clark, E. Körblova and D. M. Walba, Science, 1997, 278, 1924.

4 (a) J. Harden, B. Mbanga, N. Eber, K. Fodor-Csorba, S. Sprunt, J. T. Gleeson and A. Jákli, Phys. Rev. Lett., 2006, 97, 157802; (b) A. C. Charif, N. Diorio, K. Fodor-Csorba, J. E. Puskásad and A. Jákli, RSC Adv., 2013, 3, 17446.

5 (a) W. Iglesias, T. J. Smith, P. B. Basnet, S. R. Stefanovic, C. Tschierske, D. J. Lacks, A. Jákli and E. K. Mann, Soft Matter, 2011, 7, 9043; (b) W. Iglesias, N. L. Abbott, E. K. Mann and A. Jákli, ACS Appl. Mater. Interfaces, 2012, 4, 6884 .

6 J. Etxebarria and M. B. Ros, J. Mater. Chem., 2008, 28, 2919.

7 M. Nagaraj, Y. P. Panarin, J. K. Vij, C. Keith and C. Tschierske, Appl. Phys. Lett., 2010, 97, 213505.

8 (a) G. Dantlgraber, A. Eremin, S. Diele, A. Hauser, H. Kresse, G. Pelzl and C. Tschierske, Angew. Chem., Int. Ed., 2002, 41, 2408; (b) G. Dantlgraber, S. Diele and C. Tschierske, Chem. Commun., 2002, 2768; (c) C. Tschierske and G. Dantlgraber, Pramana, 2003, 61, 455; (d) C. Keith, R. A. Reddy, A. Hauser, U. Baumeister and C. Tschierske, J. Am. Chem. Soc., 2006, 128, 3051; (e) C. Keith, R. A. Reddy, U. Baumeister, H. Hahn, H. Lang and C. Tschierske, J. Mater. Chem., 2006, 16, 3444; ( $f$ ) H. Hahn, C. Keith, H. Lang, R. A. Reddy and C. Tschierske, Adv. Mater., 2006, 18, 2629; $(g)$ C. Keith, G. Dantlgraber, R. A. Reddy, U. Baumeister, M. Prehm, H. Hahn, H. Lag and C. Tschierske, J. Mater. Chem., 2007, 17, 3796; (h) C. Keith, G. Dantlgraber, R. A. Reddy, U. Baumeister and C. Tschierske, Chem. Mater., 2007, 19, 694; (i) Y. Zhang, U. Baumeister, C. Tschierske, M. O'Callaghan and C. Walker, Chem. Mater., 2010, 2869; (j) H. Ocak, B. BilginEran, M. Prehm and C. Tschierske, Soft Matter, 2012, 8, 7773.

9 L. E. Hough, M. Spannuth, M. Nakata, D. A. Coleman, C. D. Jones, G. Dantlgraber, C. Tschierske, J. Watanabe, E. Körblova, D. M. Walba, J. E. Maclennan, M. A. Glaser and N. A. Clark, Science, 2009, 325, 452.

10 G. Heppke, D. D. Parghi and H. Sawade, Liq. Cryst., 2000, 27, 313.

11 J. Thisayukta, Y. Nakayama, S. Kawauchi, H. Takezoe and J. Watanabe, J. Am. Chem. Soc., 2000, 122, 7441.

12 (a) R. A. Reddy and B. K. Sadashiva, Liq. Cryst., 2003, 30, 1031; (b) A. Roy, M. Gupta, S. Radhika, B. K. Sadashiva and R. Pratibha, Soft Matter, 2012, 8, 7207.

13 (a) J. Ortega, C. L. Folcia, J. Etxebarria, N. Gimeno and M. B. Ros, Phys. Rev. E: Stat., Nonlinear, Soft Matter Phys., 2003, 68, 11707; (b) N. Gimeno, A. Sanchez-Ferrer, N. Sebastian, R. Mezzenga and M. B. Ros, Macromolecules, 2011, 44, 9586.

14 M. Nagaraj, K. Usami, Z. Zhang, V. Görtz, J. W. Goodby and H. F. Gleeson, Liq. Cryst., 2014, 41, 800.

15 (a) A. Jákli, Y.-M. Huang, K. Fodor-Csorba, A. Vajda, G. Galli, S. Diele and G. Pelzl, Adv. Mater., 2003, 15, 1606; (b) W. Weissflog, M. W. Schröder, S. Diele and G. Pelzl, Adv. Mater., 2003, 15, 630.

16 (a) L. E. Hough, H. T. Jung, D. Krüerke, M. S. Heberling, M. Nakata, C. D. Jones, D. Chen, D. R. Link, J. Zasadzinski, G. Heppke, J. P. Rabe, W. Stocker, E. Körblova, 
D. M. Walba, M. A. Glaser and N. A. Clark, Science, 2009, 325, 456; (b) D. M. Walba, L. Eshat, E. Körblova and R. K. Shoemaker, Cryst. Growth Des., 2005, 5, 2091; (c) D. Chen, J. E. Maclennan, R. Shao, D. K. Yoon, H. Wang, E. Körblova, D. M. Walba, M. A. Glaser and N. A. Clark, J. Am. Chem. Soc., 2011, 133, 12656.

17 (a) J. Thisayukta, H. Takezoe and J. Watanabe, Jpn. J. Appl. Phys., Part 1, 2001, 40, 3277; (b) H. Niwano, M. Nakata, J. Thisayukta, D. R. Link, H. Takezoe and J. Watanabe, J. Phys. Chem. B, 2004, 108, 14889; (c) H. Kurosu, M. Kawasaki, M. Hirose, M. Yamada, S. Kang, J. Thisayukta, M. Sone, H. Takezoe and J. Watanabe, J. Phys. Chem. A, 2004, 108, 4674.

18 H. Kresse, J. Saltetnokova, H. Nadasi, W. Weissflog and A. Hauser, Liq. Cryst., 2001, 28, 1017.

19 V. Prasad, Liq. Cryst., 2001, 28, 1115.

20 H. Nadasi, C. Lischka, W. Weissflog, I. Wirth, S. Diele, G. Pelzl and H. Kresse, Mol. Cryst. Liq. Cryst., 2003, 399, 69.

21 J. Martinez-Perdiguero, I. Alonso, C. L. Folcia, J. Etxebarria and J. Ortega, J. Mater. Chem., 2009, 15, 5161.

22 H. Takezoe, Top. Curr. Chem., 2012, 318, 303.

23 D. K. Yoon, Y. Yi, Y. Shen, E. D. Körblova, D. M. Walba, I. I. Smalyukh and N. A. Clark, Adv. Mater., 2011, 23, 1962.

24 J. Ortega, N. Pereda, C. L. Folcia, J. Etxebarria and M. B. Ros, Phys. Rev. E: Stat. Phys., Plasmas, Fluids, Relat. Interdiscip. Top., 2000, 63, 011702.

25 G. Lee, R. J. Carlton, F. Araoka, N. L. Abbott and H. Takezoe, Adv. Mater., 2013, 25, 245.

26 E. Bialecka-Florjanczyk, I. Sledzinska, E. Górecka and J. Przedmojski, Liq. Cryst., 2008, 35, 401.

27 (a) S.-W. Choi, T. Izumi, Y. Hoshino, Y. Takanishi, K. Ishikawa, J. Watanabe and H. Takezoe, Angew. Chem., Int. Ed., 2006, 45, 1382; (b) G. Lee, R. J. Carlton, F. Araoka, N. L. Abbott and H. Takezoe, Adv. Mater., 2013, 25, 245.

28 M. Alaasar, M. Prehm and C. Tschierske, Chem. Commun., 2013, 49, 11062.

29 I. C. Pintre, J. L. Serrano, M. B. Ros, J. M.Perdiguero, I. Alonso, J. Ortega, C. Folcia, J. Etxebarria, R. Alicantee and B. Villacampa, J. Mater. Chem., 2010, 20, 2965.

30 Y. Zang, J. Martinez-Perdiguero, U. Baumeister, C. Walker, J. Etxebirra, M. Prehm, J. Ortega, C. Tschierske, M. O'Calleghan, A. Harant and M. Handschy, J. Am. Chem. Soc., 2009, 131, 18366.

31 (a) H. G. Heller and J. R. Langan, J. Chem. Soc., Perkin Trans. 1, 1981, 2, 341; (b) P. Schmitz, H. Gruler and M. Eberhardt, Mol. Cryst. Liq. Cryst., 1995, 262, 129.

32 (a) V. Prasad, S.-W. Kang and S. Kumar, J. Mater. Chem., 2003, 13, 1259; (b) V. Prasad and A. Jákli, Liq. Cryst., 2004, 31, 473; (c) V. Prasad, S.-W. Kang, X. Qi and S. Kumar, J. Mater. Chem., 2004, 14, 1495; (d) A. Jákli, V. Prasad, D. S. S. Rao, G. Liao and I. Janossy, Phys. Rev. E: Stat., Nonlinear, Soft Matter Phys., 2005, 71, 02170911; (e) N. G. Nagaveni, A. Roy and V. Prasad, J. Mater. Chem., 2012, 22, 8948; (f) C. L. Folcia, I. Alonso, J. Ortega, J. Etxebarria, I. Pintre and M. B. Ros, Chem. Mater., 2006, 18, 4617; $(g)$ I. C. Pintre, N. Gimeno, J. L. Serrano, M. B. Ros, I. Alonso, C. L. Folcia, J. Ortega and
J. Etxebarria, J. Mater. Chem., 2007, 17, 2219; (h) J. Etxebarria and M. B. Ros, J. Mater. Chem., 2008, 18, 2919; (i) I. C. Pintre, J. L. Serrano, M. B. Ros, J. M. Perdiguero, I. Alonso, J. Ortega, C. L. Folcia, J. Etxebarria, R. Alicante and B. Villacampa, J. Mater. Chem., 2010, 20, 2965; (j) M. Vijaysrinivasan, P. Kannan and A. Roy, Liq. Cryst., 2012, 39, 1465.

33 (a) M. Alaasar, M. Prehm, M. Nagaraj, J. K. Vij and C. Tschierske, Adv. Mater., 2013, 25, 2186; (b) M. Alaasar, M. Prehm, K. May, A. Eremin and C. Tschierske, Adv. Funct. Mater., 2013, 24, 1703.

34 (a) M. Alaasar, M. Prehm and C. Tschierske, Liq. Cryst., 2013, 40, 656; (b) M. Alaasar, M. Prehm and C. Tschierske, Liq. Cryst., 2014, 41, 126.

$35 \mathrm{cv}=$ crystal volumes, calculated using the increments of A. Immirzi: A. Immirzi and B. Perini, Acta Crystallogr., Sect. A: Cryst. Phys., Diffr., Theor. Gen. Crystallogr., 1977, 33, 216.

36 Very few examples of BCLCs based on 4-methylresorcinol have been reported previously: (a) U. Dunemann, M. W. Schröder, R. A. Reddy, G. Pelzl, S. Diele and W. Weissflog, J. Mater. Chem., 2005, 15, 4051; (b) W. Weissflog, G. Pelzl, H. Kresse, U. Baumeister, K. Brand, M. W. Schröder, M. G. Tamba, S. Findeisen-Tandel, U. Kornek, S. Stern, A. Eremin, R. Stannarius and J. Svoboda, J. Mater. Chem., 2010, 20, 6057.

37 C. Keith, A. Lehmann, U. Baumeister, M. Prehm and C. Tschierske, Soft Matter, 2010, 6, 1704.

38 M. J. Frisch, et al., Gaussian 09, Revision A.1, Gaussian Inc., Wallingford CT, 2009.

39 (a) S. Kang, M. Tokita, Y. Takanishi, H. Takezoe and J. Watanabe, Phys. Rev. E: Stat., Nonlinear, Soft Matter Phys., 2007, 76, 042701; (b) S. Kang, S. K. Lee, M. Tokita and J. Watanabe, Phys. Rev. E: Stat., Nonlinear, Soft Matter Phys., 2009, 80, 042703.

40 Also dielectric studies confirm the similarity of the $\mathrm{B}_{6}$ phases having short-range ordered ribbons with the $B_{1}$ phases formed by a long range $2 \mathrm{D}$ lattice of ribbons: H. Kresse, H. Schmalfuss and W. Weissflog, Liq. Cryst., 2001, 28, 799.

41 The electron density modulation occurs between the regions where alkyl chains are mixed with the central units of the bent cores (low electron density) and the regions with overlapping parts of the rod-like wings (high electron density).

42 Due to this overlapping of phase transition and crystallization the transition enthalpy values could not be determined for the $\mathrm{B}_{6}-\mathrm{DC}$ transition.

43 I. Dierking, Liq. Cryst. Today, 2003, 12, 1.

44 The difference of the transition temperatures in the cooling curves $b$ and $d$ in Fig. $5 c$ and $d$ is mainly due to the very different cooling rate used.

45 A similar texture was recently described for mixtures of $\mathrm{B}_{4}$ phases with nematic LC and was interpreted as an alignment of the helicalnanofilaments by the nematic director, we think that in our case this texture has different origin and indicates a crystalline conglomerate phase: F. Araoka, G. Sugiyamam, K. Ishikawa and H. Takezoe, Adv. Funct. Mater., 2013, 23, 2701. 
46 The molecular length in the Chevron shaped conformation (see Fig. S1 $\dagger$ ) was used for calculations; a partial intercalation of the alkyl chains, leading to a reduced tilt angle, cannot be excluded.

47 T. Otani, F. Araoka, K. Ishikawa and H. Takezoe, J. Am. Chem. Soc., 2009, 131, 12368.

48 R. A. Reddy, U. Baumeister, C. Keith and C. Tschierske, J. Mater. Chem., 2007, 17, 62.
49 H. Ocak, B. Bilgin-Eran, M. Prehm and C. Tschierske, Soft Matter, 2013, 9, 4590.

50 I. Miyake, Y. Takanishi, N. V. S. Rao, M. K. Paul, K. Ishikawa and H. Takezoe, J. Mater. Chem., 2005, 15, 4688.

51 E. Tsai, J. M. Richardson, E. Körblova, M. Nakata, D. Chen, Y. Shen, R. Shao, N. A. Clark and D. M. Walba, Angew. Chem., Int. Ed., 2013, 52, 5254. 